\title{
A global satellite environmental data record derived from AMSR-E and AMSR2 microwave Earth observations
}

\author{
Jinyang Du ${ }^{1}$, John S. Kimball ${ }^{1}$, Lucas A. Jones ${ }^{1}$, Youngwook Kim ${ }^{1}$, Joseph Glassy ${ }^{2}$, and \\ Jennifer D. Watts ${ }^{1}$ \\ ${ }^{1}$ Numerical Terradynamic Simulation Group, W.A. Franke College of Forestry and Conservation, \\ the University of Montana, Missoula, MT 59812, USA \\ ${ }^{2}$ Lupine Logic, Inc., Missoula, MT 59802, USA \\ Correspondence to: Jinyang Du (jinyang.du@ntsg.umt.edu)
}

\author{
Received: 6 April 2017 - Discussion started: 18 April 2017 \\ Revised: 11 September 2017 - Accepted: 13 September 2017 - Published: 1 November 2017
}

\begin{abstract}
Spaceborne microwave remote sensing is widely used to monitor global environmental changes for understanding hydrological, ecological, and climate processes. A new global land parameter data record (LPDR) was generated using similar calibrated, multifrequency brightness temperature $\left(T_{\mathrm{b}}\right)$ retrievals from the Advanced Microwave Scanning Radiometer for EOS (AMSR-E) and the Advanced Microwave Scanning Radiometer 2 (AMSR2). The resulting LPDR provides a long-term (June 2002-December 2015) global record of key environmental observations at a $25 \mathrm{~km}$ grid cell resolution, including surface fractional open water (FW) cover, atmosphere precipitable water vapor (PWV), daily maximum and minimum surface air temperatures $\left(T_{\mathrm{mx}}\right.$ and $\left.T_{\mathrm{mn}}\right)$, vegetation optical depth (VOD), and surface volumetric soil moisture (VSM). Global mapping of the land parameter climatology means and seasonal variability over the full-year records from AMSR-E (2003-2010) and AMSR2 (2013-2015) observation periods is consistent with characteristic global climate and vegetation patterns. Quantitative comparisons with independent observations indicated favorable LPDR performance for FW $(R \geq 0.75 ; \mathrm{RMSE} \leq 0.06)$, $\mathrm{PWV}(R \geq 0.91 ; \mathrm{RMSE} \leq 4.94 \mathrm{~mm}), T_{\mathrm{mx}}$ and $T_{\mathrm{mn}}\left(R \geq 0.90 ; \mathrm{RMSE} \leq 3.48^{\circ} \mathrm{C}\right)$, and $\operatorname{VSM}\left(0.63 \leq R \leq 0.84\right.$; bias-corrected RMSE $\left.\leq 0.06 \mathrm{~cm}^{3} \mathrm{~cm}^{-3}\right)$. The LPDR-derived global VOD record is also proportional to satellite-observed NDVI (GIMMS3g) seasonality $(R \geq 0.88)$ due to the synergy between canopy biomass structure and photosynthetic greenness. Statistical analysis shows overall LPDR consistency but with small biases between AMSR-E and AMSR2 retrievals that should be considered when evaluating long-term environmental trends. The resulting LPDR and potential updates from continuing AMSR2 operations provide for effective global monitoring of environmental parameters related to vegetation activity, terrestrial water storage, and mobility and are suitable for climate and ecosystem studies. The LPDR dataset is publicly available at http://files.ntsg.umt.edu/data/LPDR_v2/.
\end{abstract}

\section{Introduction}

Earth's atmospheric, biophysical, and hydrological processes are closely coupled (Walko et al., 2000; Trenberth et al., 2007) and respond to altered climate forcing manifested by changes in key environmental variables (Meehl et al., 2007). Integrated and consistent measurements of Earth system environmental variables at the global scale are needed for advancing our understanding of interconnected Earth systems (Trenberth et al., 2007) and for addressing criti- cal global-change-related questions including global water cycle intensification (Huntington, 2006; Wild et al., 2008; Déry et al., 2009), arctic amplification, and feedbacks to climate change (Smith et al., 2005; Grosse et al., 2011), and the primary drivers behind global vegetation changes (Zhu et al., 2016).

Complementary to optical-thermal infrared (IR) and active microwave remote sensing, spaceborne passive microwave radiometers allow for measurements of global en- 
vironmental variables at a relatively coarse spatial resolution $(\sim 5$ to $100 \mathrm{~km})$ but with relatively high temporal fidelity ( $\sim$ daily for higher latitudes $\geq 45^{\circ} \mathrm{N}$ ) and with reduced constraints from variable solar illumination, clouds, and atmosphere aerosol contamination effects (Ulaby et al., 2014). While lower-frequency (e.g., L-band) sensors, including the ESA Soil Moisture and Ocean Salinity (SMOS) and NASA Soil Moisture Active Passive (SMAP) missions, are generally considered optimal for detecting soil and surface water signals under moderate to high vegetation biomass conditions (Kerr et al., 2001; Entekhabi et al., 2010), higherfrequency sensors, such as AMSR-E (Koike et al., 2004) and AMSR2 (Imaoka et al., 2012), provide simultaneous multichannel (C- to W-band) $T_{\mathrm{b}}$ observations with variable sensitivity to surface water, soil, vegetation, and atmosphere conditions (Njoku et al., 2003; Jones et al., 2010). The combined observations allow for the distinguishing of individual land parameter signals from background noise. However, the major AMSR-E and AMSR2 (hereafter denoted as AMSR-E/2) algorithms have largely focused on singleparameter retrievals, including the NASA and JAXA standard soil moisture products (Njoku et al., 2003; Koike et al., 2004). In contrast, the University of Montana (UMT) global Land Parameter Data Record version 1 (LPDR v1) was developed to exploit AMSR-E multifrequency $T_{\mathrm{b}}$ observations for global daily mapping of multiple synergistic land parameters related to the status and storage of water in the atmosphere, vegetation, and soil (Jones et al., 2010; Jones and Kimball, 2010). The LPDR v1 database has been applied for a variety of environmental studies, including quantifying surface water inundation impacts on tundra methane emissions (Watts et al., 2014), boreal wildfire disturbance and recovery assessments (Jones et al., 2013), evaluating hydroclimatic controls on vegetation phenology (Alemu and Henebry, 2013; Guan et al., 2014), biodiversity modeling and prediction (Waltari et al., 2014), and vector-borne disease risk assessments (Chuang et al., 2012). The LPDR v1 has also served as a baseline for evaluating other AMSR-E algorithm retrievals (Mladenova et al., 2014) and refinements (Jang et al., 2014; Du et al., 2014). The LPDR v1 encompasses the AMSR-E record (2002-2011), while similar observations from AMSR2 enable potential LPDR continuity (Du et al., 2014).

In this investigation, the version 2.0 UMT Land Parameter Data Record (henceforth denoted as LPDR) was generated by incorporating recent algorithm improvements ( $\mathrm{Du}$ et al., 2015, 2016a), new algorithm refinements, and an extended AMSR-E/2 satellite record. The key satellite microwave land parameter retrievals derived from this study include daily maximum and minimum surface air temperature ( $T_{\mathrm{mx}}$ and $T_{\mathrm{mn}}$ ), atmosphere precipitable water vapor (PWV), vegetation optical depth (VOD), surface fractional open water cover (FW), and volumetric soil moisture (VSM). Surface air temperature, defined as air temperature at approximately $2 \mathrm{~m}$ of height in this study and used as a global warming indicator (Hansen and Lebedeff, 1987; Jones et al., 1999), integrates key information on the thermal state of the landatmosphere interface (Jones et al., 2010). PWV represents the total water content of the atmosphere column within the satellite sensor field of view (Bedka et al., 2010) and is strongly interactive with temperature and climate (Held and Soden, 2000; Wentz et al., 2007). The VOD parameter represents the slant-path opacity of the intervening vegetation layer to land surface microwave emissions; VOD is microwave frequency dependent and sensitive to changes in canopy biomass water content, including woody and foliar elements (Shi et al., 2008; Jones et al., 2011; Liu et al., 2011). The FW parameter is an important hydrological and biogeochemical variable (Watts et al., 2012), while largescale mapping of FW dynamics has been used for studying high-latitude ecosystems, wetlands, and carbon-cycle-related feedbacks to climate change (Van Huissteden et al., 2011; McVicar et al., 2012; Lupascu et al., 2014). Another key parameter is surface soil moisture, which governs the exchanges of water, energy, and carbon between the soil and atmosphere (Entekhabi et al., 2010); soil moisture is defined in this study as the volume of water in a given volume of soil. The relative depth of soil moisture sensitivity is dependent on microwave frequency and land surface conditions but is generally limited to the top $(\sim 1 \mathrm{~cm}$ depth $)$ soil layer using moderate-frequency (e.g., C-, X-band) $T_{\mathrm{b}}$ retrievals from the AMSR-E/2 sensors.

The goals of this study were to (a) provide an enhanced data record over prior (v1) LPDR releases in terms of both retrieval accuracy and temporal coverage, (b) generate consistent retrievals from AMSR-E and AMSR2 suitable for long-term evaluations of key land parameters important to ecosystem processes, and (c) facilitate LPDR utility for the Earth science community by providing detailed descriptions of algorithm structure, retrieval accuracy and product performance, and data format specifications. The LPDR methods, data processing, global performance, and uncertainty assessments are presented below.

\section{Methods}

\subsection{LPDR $v 1$ algorithm and refinements}

In the LPDR v1 algorithms, the satellite-observed microwave emission from land overlying a non-scattering atmosphere is theoretically described by three components representing the upward emission of the atmosphere, land surface upward emission attenuated by the atmosphere, and the downward atmosphere emission reflected by the land surface and attenuated by atmosphere (Wang and Manning, 2003; Jones et al., 2010). Atmosphere effects are mainly determined by air temperature and the optical depth of oxygen, cloud liquid water, and atmosphere water vapor (Wentz and Meissner, 2000; Jones et al., 2010). The land surface upward microwave emission is represented as the overall emission from 
a mix of land surface features, including open water, vegetation, and soil (Mo et al., 1982; Jones et al., 2010). The AMSR-E/2 frequencies have variable sensitivity to land and atmosphere properties, and the frequency-dependent optical depth of vegetation or atmospheric layers determines the degree to which measured microwave emissions originate from the soil, vegetation, or atmosphere (Jones, 2016). The Cand X-band AMSR-E/2 measurements are generally used for inferring soil moisture under vegetation and atmosphere layers, while higher $T_{\mathrm{b}}$ frequencies $(>18 \mathrm{GHz})$ show relatively greater sensitivity to atmospheric properties (Njoku et al., 2003). In addition, open water may significantly impact the measured microwave emissions at all AMSR-E/2 frequencies due to the high dielectric constant of water (Jones et al., 2010; Du et al., 2016b). Based on the above theory and considerations, the LPDR v1 algorithms utilize observations at relatively high frequencies $(>18 \mathrm{GHz})$ to estimate PWV and FW and then apply the inferred information to derive the X-band VOD and VSM retrievals. The two-step retrieval process is detailed as follows: first, effective surface temperature $\left(T_{\mathrm{s}}\right), T_{\mathrm{mx}}$ and $T_{\mathrm{mn}}, \mathrm{FW}$, and PWV are obtained using an iterative algorithm approach that incorporates $\mathrm{H}$ - and $\mathrm{V}$-polarized 18.7 and $23.8 \mathrm{GHz} T_{\mathrm{b}}$ data and several temperature-insensitive microwave indices (Jones et al., 2010). In this step, a simplified land emission model that considers constant dry soil emissivity is adopted for facilitating the inversion process. The X-band VOD is then obtained by inverting the land-water microwave emissivity slope index, and surface ( $\sim 0-1 \mathrm{~cm}$ depth) VSM is acquired after correcting for X-band atmosphere, $\mathrm{FW}$, and vegetation effects (Jones et al., 2010). More detailed descriptions of the LPDR v1 algorithms are provided elsewhere (Jones et al., 2010). Recent refinements based on the LPDR v1 algorithm framework were carried out separately using AMSR-E or AMSR2 $T_{\mathrm{b}}$ observations, including (a) an empirical calibration of the AMSR2 PWV retrieval based on similar observations from the Atmospheric Infrared Sounder (AIRS; Du et al., 2015), (b) a refined AMSR2 estimation of $T_{\mathrm{mx}}$ and $T_{\mathrm{mn}}$ that considers terrain and latitude effects (Du et al., 2015), and (c) an improved AMSR-E VSM retrieval using a weighted averaging strategy and dynamic selection of vegetation-scattering albedos (Du et al., 2016a).

\subsection{LPDR retrieval algorithms}

The latest (v2) LPDR algorithms were developed based on the available algorithm framework and improvements (Sect. 2.1). For generating a consistent LPDR product, the available algorithm refinements were adapted for both AMSR-E and AMSR2 portions of the combined, calibrated $T_{\mathrm{b}}$ record (Sect. 3.1). The final regression formulas for estimating PWV are described below, which follow from Du et al. (2015) but use different regression coefficients; for the satellite ascending (PM) overpass, the empirical calibration resulted in

$$
\begin{aligned}
& \mathrm{PWV}_{\mathrm{PM}}=-4.06+0.22 T_{\mathrm{s}} \\
& +\frac{A_{\mathrm{vd}}}{a_{\mathrm{v} 23}-a_{\mathrm{v} 18}}(0.47+0.26 \exp (-H)) \\
& -1.63 \log \left(\frac{\Delta T_{\mathrm{b}}(89.0)}{\Delta T_{\mathrm{b}}(36.0)}\right)
\end{aligned}
$$

and for the descending (AM) overpass it was

$$
\begin{aligned}
& \mathrm{PWV}_{\mathrm{AM}}=1.06+0.27 T_{\mathrm{s}} \\
& +\frac{A_{\mathrm{vd}}}{a_{\mathrm{v} 23}-a_{\mathrm{v} 18}}(0.48+0.21 \exp (-H)) \\
& -1.63 \log \left(\frac{\Delta T_{\mathrm{b}}(89.0)}{\Delta T_{\mathrm{b}}(36.0)}\right)
\end{aligned}
$$

The PWV estimate is derived by a weighted sum of $T_{\mathrm{S}}\left({ }^{\circ} \mathrm{C}\right)$, atmosphere optical depth $A_{\mathrm{vd}}$ estimated from the 23.8 and 18.7 $\mathrm{GHz} T_{\mathrm{b}}$ polarization difference ratios, a cloud correction term $\frac{\Delta T_{\mathrm{b}}(89.0)}{\Delta T_{\mathrm{b}}(36.0)}$, and surface elevation $H(\mathrm{~km})$. The terms $a_{\mathrm{v} 18}$ and $a_{\mathrm{v} 23}$ are empirically derived water vapor absorption coefficients (Jones et al., 2010). The regression formulas for estimating $T_{\mathrm{mx}}$ and $T_{\mathrm{mn}}$ are given as

$$
\begin{aligned}
& T_{\mathrm{mn}}=3.55+0.69 T_{\mathrm{s}}+11.86 T_{\mathrm{c}}-6.67 T_{\mathrm{c}}^{2}-0.14(\mathrm{abs}(\mathrm{Lat})) \\
& \quad+2.74 \gamma \cos (t)+1.83 \cdot \log (\mathrm{FW}+1.0) \\
& T_{\mathrm{mx}}=7.49+0.79 T_{\mathrm{s}}-5.71 T_{\mathrm{c}}+11.45 T_{\mathrm{c}}^{2}-0.14(\mathrm{abs}(\mathrm{Lat})) \\
& \quad+2.20 \gamma \cos (t)+1.75 \cdot \log (\mathrm{FW}+1.0)
\end{aligned}
$$

where $T_{\mathrm{S}}$ is the effective surface temperature and $T_{\mathrm{c}}$ is the frequency-dependent vegetation transmissivity, which is $T_{\mathrm{c}}=\exp (-\mathrm{VOD}) ; t=2 \pi \omega-\pi ; \omega=\frac{\text { doy }}{n} ; \gamma=\operatorname{sign}(\mathrm{Lat})(1-$ $\left.\frac{\operatorname{abs}(\operatorname{abs}(\mathrm{Lat})-45)}{45}\right)$ in which doy is the day of year, $n$ is the total days in a year, and Lat is the geographic latitude. FW is the fractional proportion (\%) of standing water cover within a grid cell and is used for minimizing open water impacts on the temperature retrievals.

In addition to the above updates, we performed additional FW calibration for improving the VSM retrievals in this study. As described above, the iterative retrieval algorithm proposed in Jones et al. (2010) and revised in Du et al. (2015) assumes dry soil conditions for estimating FW, VOD, and atmosphere properties. Consequently, the FW retrieval is likely to be affected by a soil moisture signal when the simplified dry soil assumption is not fully satisfied. Therefore, an empirical calibration of AMSR-E/2 FW was made for the purpose of improving the soil moisture inversion as follows: (a) AMSR-E FW values for the nonfrozen period over the 2003-2010 record were averaged for each $25 \mathrm{~km}$ grid cell and compared with an ancillary MODIS 250 m MOD44W static FW map (Carroll et al., 2009); (b) the resulting AMSR-E FW summer average values were grouped into 1000 population ranges from 0.0 to 1.0 and 0.001 intervals; (c) for each group, mean AMSR-E FW and corresponding MOD44W values were calculated; and (d) relationships between AMSR-E and MOD44W FW retrievals 
were analyzed based on their mean group values and derived for two respective conditions, AMSR-E FW $<0.15$ and $\mathrm{FW} \geq 0.15$. The $0.15 \mathrm{FW}$ threshold was selected for describing the AMSR-E and MOD44W FW relationships over the different AMSR-E FW levels. Soil moisture was then estimated after open water correction using the calibrated FW record (denoted as $F W_{\text {cal }}$ ). The resulting empirical relationships were used for calibrating AMSR-E/2 ascending (PM) and descending (AM) FW estimates prior to their use in VSM retrievals against the MOD44W open water maps:

$\mathrm{FW}_{\text {cal_PM }}=4.4267 \mathrm{FW}^{3}+1.3447 \mathrm{FW}^{2}+0.4114 \mathrm{FW} \mathrm{FW}<0.15$

$\mathrm{FW}_{\text {cal_PM }}=-0.4683 \mathrm{FW}^{2}+1.0182 \mathrm{FW}-0.0458 \quad \mathrm{FW} \geq 0.15$,

$\mathrm{FW}_{\text {cal_AM }}=-23.752 \mathrm{FW}^{3}+7.7518 \mathrm{FW}^{2}+0.1565 \mathrm{FW} \quad \mathrm{FW}<0.15$

$\mathrm{FW}_{\text {cal_AM }}=-0.4014 \mathrm{FW}^{2}+0.9837 \mathrm{FW}-0.0422 \quad \mathrm{FW} \geq 0.15$.

Here we note that the ancillary MOD44W map was used solely for open water correction of the VSM estimates and is independent from the LPDR FW retrievals. The general LPDR retrieval process is illustrated in Fig. 1.

\subsection{Evaluation of the LPDR}

The resulting LPDR environmental parameters for nonfrozen land surface conditions were evaluated based on their full-year records (2003-2010 and 2013-2015) and following similar approaches used in previous studies (Jones et al., 2010; Du et al., 2015, 2016a). The evaluations included analyzing the global distributions of climatological means and standard deviation (SD) or coefficient of variation (CV) in LPDR full-year records. The LPDR ascending and descending retrievals have similar spatial distributions, so only the ascending result maps are presented in the following analysis. To compare with the LPDR results, similar climatological mean and CV maps (if applicable) from alternative reference data were utilized, including MOD44W FW, normalized difference vegetation index (NDVI) observations from the third-generation Global Inventory Monitoring and Modeling System project record (GIMMS3g; Tucker et al., 2005; Pinzon and Tucker, 2014), and (AIRS) PWV (Divakarla et al., 2006).

Global seasonal cycles defined from monthly means and $\mathrm{CV}$ variations in the LPDR daily observations and full-year data records were compared against similar aggregations from the reference data, including GIMMS3g NDVI and AIRS PWV. In particular, the vegetation seasonality indicated by VOD and NDVI was compared for the global domain and six major plant functional types.

The LPDR-derived FW composites over the 20032010 (representing AMSR-E) and 2013-2015 (representing AMSR2) periods were compared against the MOD44W static open water map. While the MOD44W record is used for surface water correction of $T_{\mathrm{b}}$ observations for the soil

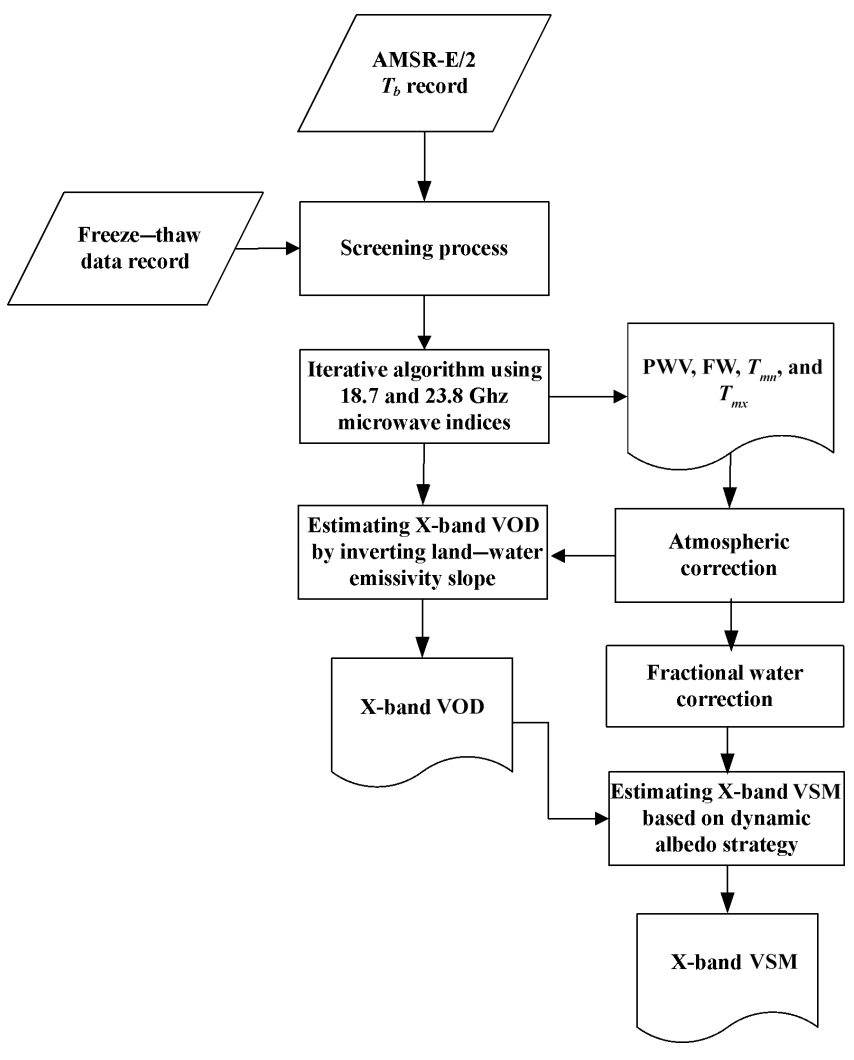

Figure 1. The LPDR algorithm retrieval process.

moisture retrievals (Eqs. 5 and 6), the correction is independent of the LPDR FW retrieval (Jones et al., 2010). The LPDR-derived $T_{\mathrm{mx}}$ and $T_{\mathrm{mn}}$ estimates were compared with independent daily air temperature measurements from 142 World Meteorological Organization (WMO) sites for the selected years 2010 (representing AMSR-E) and 2013 (representing AMSR2). The LPDR-derived PWV results were analyzed against AIRS PWV observations from the same 142 WMO site locations for the 2010 and 2013 periods. Finally, the LPDR-derived daily VSM results were compared against independent surface soil moisture measurements from four regional soil station networks. The metrics used to evaluate agreement between the LPDR results and independent observations included correlation coefficient $(R)$, root mean square error (RMSE), and bias.

For evaluating LPDR consistency, only grid cells with high-quality retrievals were considered in the analysis, which excluded areas with higher vegetation biomass cover (VOD $>2.3$ representing over $90 \%$ loss of underlying soil and open water signals from vegetation attenuation) or where the difference between V-pol and H-pol $T_{\mathrm{b}}$ retrievals at 18 or $23 \mathrm{GHz}$ was less than $1.0 \mathrm{~K}$ (i.e., indicating microwave signal saturation). Grid cells containing large water bodies (FW > 0.2) were also excluded to avoid excessive contamination of the land signal by open water (Du et al., 2015; Jones, 2016). Moreover, we divided 365 (366 for leap year) 
days of a year into 122 3-day periods and for each 3-day period selected for the consistency evaluation, we required at least one high-quality retrieval within the period for each year of the 2003-2010 and 2013-2015 portions of the record. Based on the above data selection criteria, the global monthly mean of the high-quality LPDR daily estimates were calculated for each month of the AMSR-E (2003-2010) and AMSR2 (2013-2015) full-year records and analyzed using statistical metrics, including mean, $\mathrm{SD}$, and range.

\section{Data processing and ancillary datasets}

\subsection{AMSR-E and AMSR2 $T_{\mathrm{b}}$ records used for land parameter retrievals}

Multifrequency $T_{\mathrm{b}}$ observations from AMSR-E and AMSR2 provide the primary inputs for LPDR processing. The AMSR-E sensor was launched on 4 May 2002 onboard the NASA EOS Aqua satellite and operated until 4 October 2011. AMSR-E was succeeded by AMSR2, which was launched on 18 May 2012 onboard the JAXA GCOM$\mathrm{W} 1$ satellite. Both sensors provide global measurements of vertically $(\mathrm{V})$ and horizontally $(\mathrm{H})$ polarized microwave emissions at six frequencies $(6.9,10.7,18.7,23.8,36.5$, $89.0 \mathrm{GHz}$ ) with descending and ascending orbital equatorial crossings at 01:30 and 13:30 local time. Though succeeding most characteristics of its predecessor, AMSR2 is different from AMSR-E in several aspects, including (a) an additional $T_{\mathrm{b}}$ channel at $7.3 \mathrm{GHz}$ designed for mitigating radio frequency interference (RFI), (b) a larger (2.0 m diameter) main reflector providing enhanced spatial resolution retrievals, and (c) an improved calibration system (Imaoka et al., 2010).

For developing a consistent global land parameter record, the AMSR-E/2 $T_{\mathrm{b}}$ retrievals were preprocessed in four steps. (1) AMSR-E orbital swath $T_{\mathrm{b}}$ data from the Remote Sensing Systems (RSS) version 7 product were spatially resampled and re-projected to a $25 \mathrm{~km}$ resolution global Equal-Area Scalable Earth (EASE) Grid version 1 format following previously established methods (Armstrong and Brodzik, 1995; Ashcroft and Wentz, 1999; Brodzik and Knowles, 2002). In this study, an additional altitude correction of the $T_{\mathrm{b}}$ orbital swath retrievals was made to improve sensor footprint geolocation accuracy prior to the gridding process. The altitude correction to the AMSR2 L1R data considers the actual surface of the Earth instead of an ideal Earth ellipsoid (T. Maeda et al., 2016), which helps to ensure reliable analysis of AMSR-E/2 land surface retrievals over high elevation areas, including the Qinghai-Tibetan Plateau; (2) a similar gridding process was performed on the AMSR2 L1R swath data. (3) The AMSR2 multifrequency (X-to W-band) $T_{\mathrm{b}}$ retrievals were empirically calibrated against the same AMSR-E channels using similar overlapping $T_{\mathrm{b}}$ observations from the Microwave Radiation Imager (MWRI) onboard the Chinese FY3B satellite (Du et al., 2014). However, in con- trast to $\mathrm{Du}$ et al. (2014) in which the $T_{\mathrm{b}}$ calibration was conducted on a per grid cell basis for each frequency, polarization, and orbit, the approach used for this investigation involved calibrating within $5 \times 5$ grid cell windows to minimize the impact of the different sensor footprints. Both ascending- and descending-orbit $\mathrm{X}$-band $T_{\mathrm{b}}$ data for a given polarization were calibrated together because the largest differences and lowest correlations were found between overlapping MWRI and AMSR-E/2 X-band observations among all sensor frequencies utilized (Du et al., 2014). The combined orbit X-band calibration was also found to produce better consistency between the AMSR2 ascending and descending X-band VOD retrievals, which are particularly sensitive to $T_{\mathrm{b}}$ calibration uncertainties, especially for higher vegetation biomass conditions. (4) Finally, the gridded and calibrated AMSR-E/2 $T_{\mathrm{b}}$ data were subjected to additional screening prior to implementing the retrieval algorithms to minimize potential noise effects from RFI, active precipitation, frozen conditions, and permanent ice and snow cover using previously established methods (Jones et al., 2010). The $T_{\mathrm{b}}$ screening under frozen land surface conditions was identified using an existing global daily freeze-thaw (FT) data record derived from a refined classification algorithm (Kim et al., 2017) and AMSR-E/2 $36.5 \mathrm{GHz}$ V-polarized $T_{\mathrm{b}}$ retrievals in a consistent $25 \mathrm{~km}$ resolution global EASE-Grid projection format; the FT mask is represented as a grid-cellwise daily binary bit flag in the LPDR dataset and was used to identify and screen frozen land surface conditions from further LPDR processing and retrievals (Fig. 1).

\subsection{Ancillary data used for algorithm calibration and LPDR performance assessment}

A variety of ancillary data were used for calibrating the LPDR algorithms and evaluating LPDR global performance. The ancillary data included atmosphere PWV retrievals from AIRS (Divakarla et al., 2006), a static MOD44W open water map (Carroll et al., 2009), GIMMS3g NDVI (Pinzon and Tucker, 2014), and in situ surface soil moisture measurements from four globally distributed measurement networks (Jackson et al., 2010; Yang et al., 2013; Smith et al., 2012). All ancillary data were re-projected to the same $25 \mathrm{~km}$ EASE-Grid version 1 format as the LPDR to facilitate algorithm calibration and product comparisons.

The AIRS PWV products were used for LPDR PWV algorithm calibration and product comparisons. The LPDR iterative retrieval algorithm for PWV (Jones et al., 2010; Sect. 2.1) was empirically calibrated and quantitatively validated using synergistic PWV observations (version 6 level 2 swath product) from AIRS and the Advanced Microwave Sounding Unit (AMSU) instruments (Du et al., 2015). Both AIRS and AMSU are deployed on the Aqua satellite together with AMSR-E and have the same local overpass time as AMSR2. The AIRS version 6 product is expected to have higher accuracy than the previous AIRS version 4 water va- 


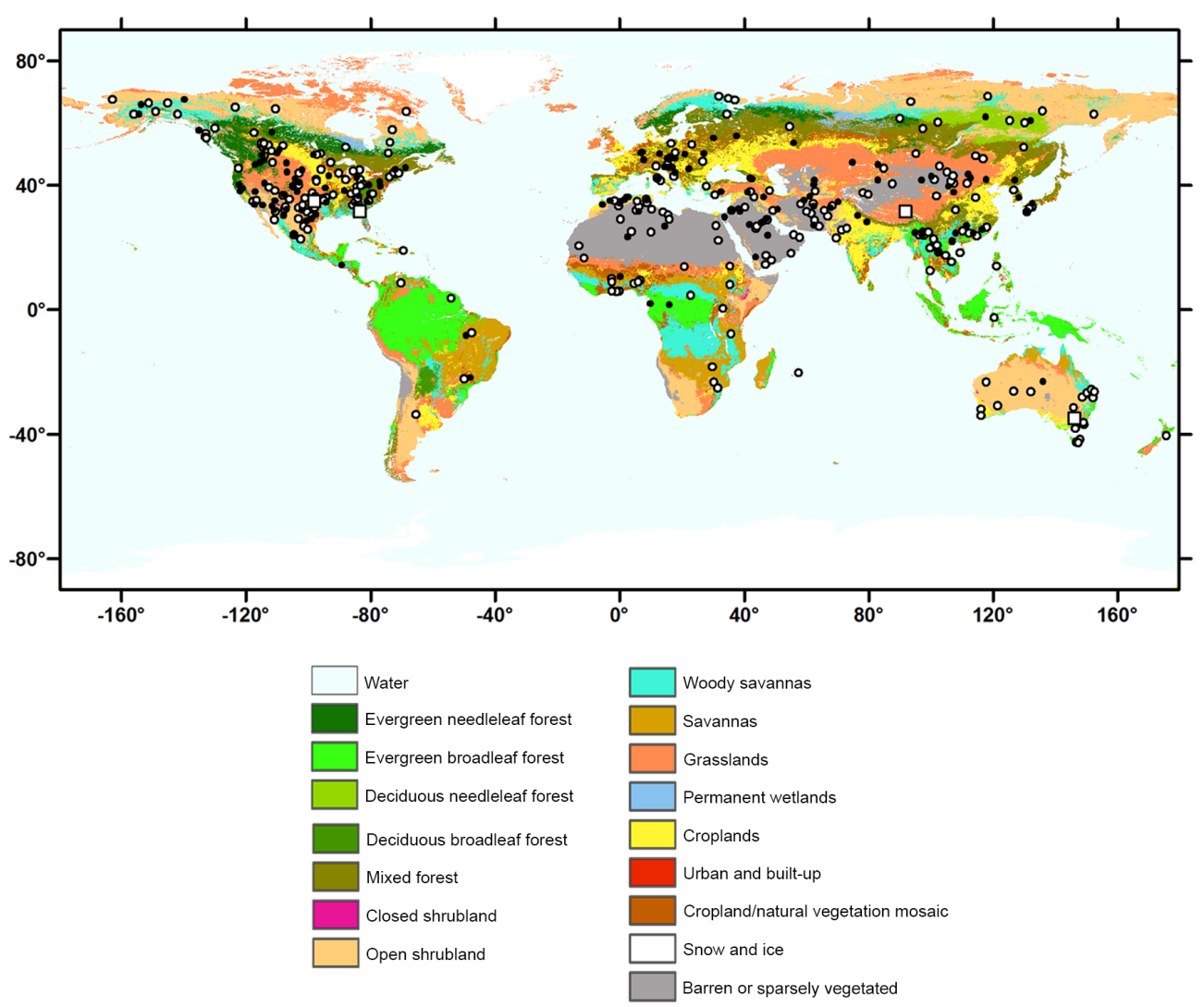

Figure 2. Global distribution of WMO weather station locations where collocated AIRS observations and WMO air temperature measurements were used for calibrating (white circles) and validating (black circles) the LPDR PWV, $T_{\mathrm{mx}}$, and $T_{\mathrm{mn}}$ estimates; the locations of the four independent soil moisture networks used for validating the LPDR VSM retrievals are also shown (white rectangles).

por record, which shows retrieval uncertainties of less than $15 \%$ in comparison with radiosonde measurements in $2 \mathrm{~km}$ troposphere layers (Divakarla et al., 2006; Diao et al., 2013).

For calibrating LPDR-derived PWV, $T_{\mathrm{mx}}$, and $T_{\mathrm{mn}}$ retrievals over different land cover types, in situ daily $T_{\mathrm{mx}}$ and $T_{\mathrm{mn}}$ measurements were obtained along with coincident AIRS PWV retrievals for year 2010 from 250 globally distributed WMO weather station locations (Fig. 2). The spatial distribution of the WMO stations selected was designed to be representative of major global land cover classes (Justice et al., 2002; Friedl et al., 2010). The WMO air temperature record was obtained from the National Climate Data Center (NCDC) Global Summary of the Day (GSOD version 7) using previously established criteria (Jones et al., 2010). The calibration was made for the year 2010 and the derived relationships were applied to the entire AMSR-E/2 record. Independent daily air temperature measurements and collocated AIRS PWV retrievals from 142 other globally distributed WMO weather stations (Fig. 2) operating from 2010 to 2013 were selected for the evaluation of LPDR-derived $T_{\mathrm{mx}}, T_{\mathrm{mn}}$, and PWV accuracy; relative consistency in performance between the AMSR-E (represented by the year 2010) and AMSR2 (represented by the year 2013) portions of the LPDR record was also assessed.

The LPDR-derived FW record was evaluated against the higher-resolution $(250 \mathrm{~m})$, global-scale MOD44W static open water product (Carroll et al., 2009). The MOD44W product is derived from a compilation of the SRTM (Shuttle Radar Topography Mission) water body dataset and the MODIS MOD44C Collection 5 (2000-2008) open water classification (Haran et al., 2005; Carroll et al., 2009). The MOD44W map was re-projected and aggregated to the same $25 \mathrm{~km}$ EASE-Grid format as the LPDR prior to the comparisons.

The LPDR-derived VOD record was evaluated over the global domain using synergistic satellite optical-IR observations of vegetation greenness defined from NDVI. The GIMMS3g (version 1) global NDVI record derived from calibrated NOAA Advanced Very High Resolution Radiometer (AVHRR) sensor observations (Pinzon and Tucker, 2014) has been widely used in evaluating global vegetation status and changes (Zhu et al., 2016); the bimonthly NDVI data were re-projected from their native $1 / 12^{\circ}$ spatial resolution and geographic projection format to the same $25 \mathrm{~km}$ resolution global EASE-Grid format as the LPDR for the 2003 to 2015 
record. The NDVI is sensitive to changes in vegetation greenness and differs from LPDR-derived $10.65 \mathrm{GHz}$ VOD sensitivity to canopy biomass and water content variations, including both photosynthetic (e.g., foliar) and non-photosynthetic (e.g., stem and branch) elements (Jones et al., 2013). Both satellite NDVI and VOD records have been shown to provide similar synergistic canopy phenology metrics distinguishing both seasonal and spatial differences among different plant functional types (Jones et al., 2011).

The LPDR VSM retrieval accuracy was evaluated using a similar approach as Du et al. (2016a) by comparing the satellite X-band $(10.65 \mathrm{GHz})$ daily soil moisture retrievals against collocated in situ surface soil moisture measurements from four globally distributed soil moisture measurement networks (Fig. 2). The four soil moisture regional networks represent the approximate spatial heterogeneity and sensing depth as the AMSR-E/2 $T_{\mathrm{b}}$ footprint retrievals and were designed for validating satellite regional soil moisture retrievals as detailed in Jackson et al. (2010), Smith et al. (2012), and Yang et al. (2013). The Little River network (LR; centroid $83.61^{\circ} \mathrm{W}, 31.65^{\circ} \mathrm{N}$ ) has a humid climate representing forest, cropland, and pasture vegetation (Jackson et al., 2010). The Little Washita network ( $\mathrm{LW}$; centroid $98.1^{\circ} \mathrm{W}, 34.95^{\circ} \mathrm{N}$ ) has a subhumid climate dominated by rangeland and pasture vegetation (Jackson et al., 2010). A 3-year (2003-2005) LR and LW daily soil moisture record representing surface (0$5 \mathrm{~cm}$ of depth) soil layer conditions was used for this study. The Nagqu (NQ; centroid $91.875^{\circ} \mathrm{E}, 31.625^{\circ} \mathrm{N}$ ) soil moisture network was located on the Tibetan Plateau in western China. Surface soil moisture measurements extending from August 2010 to September 2011 from the NQ network were used for evaluating LPDR performance in an environment characterized as high elevation with large surface soil moisture variability and sparse vegetation (Chen et al., 2013; Yang et al., 2013). The Yanco (YC; centroid $\left.146.0915^{\circ} \mathrm{E}, 34.842^{\circ} \mathrm{S}\right)$ network is part of the larger Murrumbidgee Soil Moisture Monitoring Network (MSMMN) in Australia (Smith et al., 2012; Panciera et al., 2014) and represents a Southern Hemisphere semiarid agricultural and grazing landscape; a 2-year (2009-2010) YC surface soil moisture record was also used for this study.

\section{Results}

\subsection{Fractional open water}

The LPDR FW composites (Fig. 3a) for nonfrozen periods capture characteristic global inundation patterns consistent with the ancillary MOD44W static water map (Fig. S1 in the Supplement), including extensive wetland complexes in the pan-Arctic region, Bangladesh, and Argentina and major river systems such as the Amazon, Mississippi, Yangtze, and Yenisei. Large FW seasonal variations (Fig. 3b) associated with seasonal precipitation and/or snowmelt events occur over the Mississippi basin, the Paraná River basin, north-
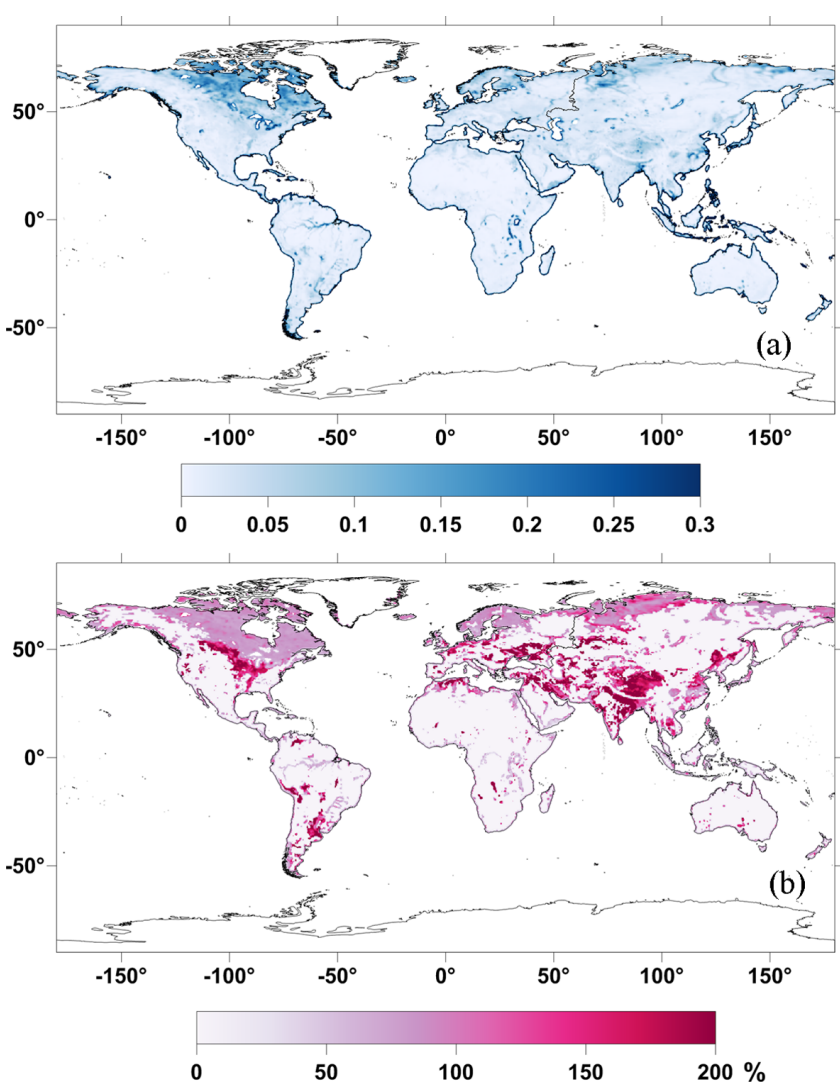

Figure 3. LPDR fractional water mean (a) and 2 times the coefficient of variation (b) over the years 2003-2010 and 2013-2015.

ern Canada and Eurasia, the Indian subcontinent, southern Tibet, and eastern China. The LPDR FW record also distinguishes dynamic flooding events not represented by the ancillary static water map, including extensive water inundation (Fig. 3a) and large seasonal FW variations (Fig. 3b) in Bangladesh where the summer monsoon brings large precipitation-driven flooding (Brouwer et al., 2007).

Quantitative comparisons of LPDR FW annual means in relation to MOD44W were made for respective AMSRE (2003-2010) and AMSR2 (2013-2015) full-year records (Table 1). Both AMSR2 and AMSR-E FW annual means show favorable spatial correspondence with the MOD44W results $(R \geq 0.75$, RMSE $\leq 0.06)$. The LPDR inundated area percentage also shows a mean $1.50 \%$ wet bias relative to the MOD44W product, which may partially result from better LPDR microwave sensitivity to surface water dynamics, including water beneath vegetation (Du et al., 2016b). Higher LPDR FW levels along coastlines are due to larger water cover of coastal grid cells within the land mask. The LPDR results also show generally larger coastal $\mathrm{FW}$ levels than MOD44W, indicating ocean contamination of adjacent land grid cells within the coarser AMSR-E/2 $T_{\mathrm{b}}$ footprint. 
Table 1. Comparisons of FW global averages over AMSR-E (2003-2010) and AMSR2 (2013-2015) periods in relation to the MOD44W static open water map. All products were projected into a consistent $25.0 \mathrm{~km}$ resolution EASE-Grid format; positive and negative bias indicates FW overestimation and underestimation, respectively, relative to the static water map.

\begin{tabular}{|c|c|c|c|c|c|c|}
\hline \multicolumn{7}{|c|}{ AMSR-E/2 FW vs. MOD44W } \\
\hline & \multicolumn{2}{|c|}{$R$} & \multicolumn{2}{|c|}{ RMSD } & \multicolumn{2}{|c|}{ Bias } \\
\hline & Asc & Dsc & Asc & Dsc & Asc & Dsc \\
\hline AMSR-E & 0.767 & 0.750 & 0.057 & 0.057 & 0.016 & 0.012 \\
\hline AMSR2 & 0.795 & 0.775 & 0.054 & 0.054 & 0.017 & 0.013 \\
\hline
\end{tabular}

$R$ denotes Pearson correlation coefficient; RMSD denotes root mean square difference; Asc and Dsc denote respective ascending and descending orbits.

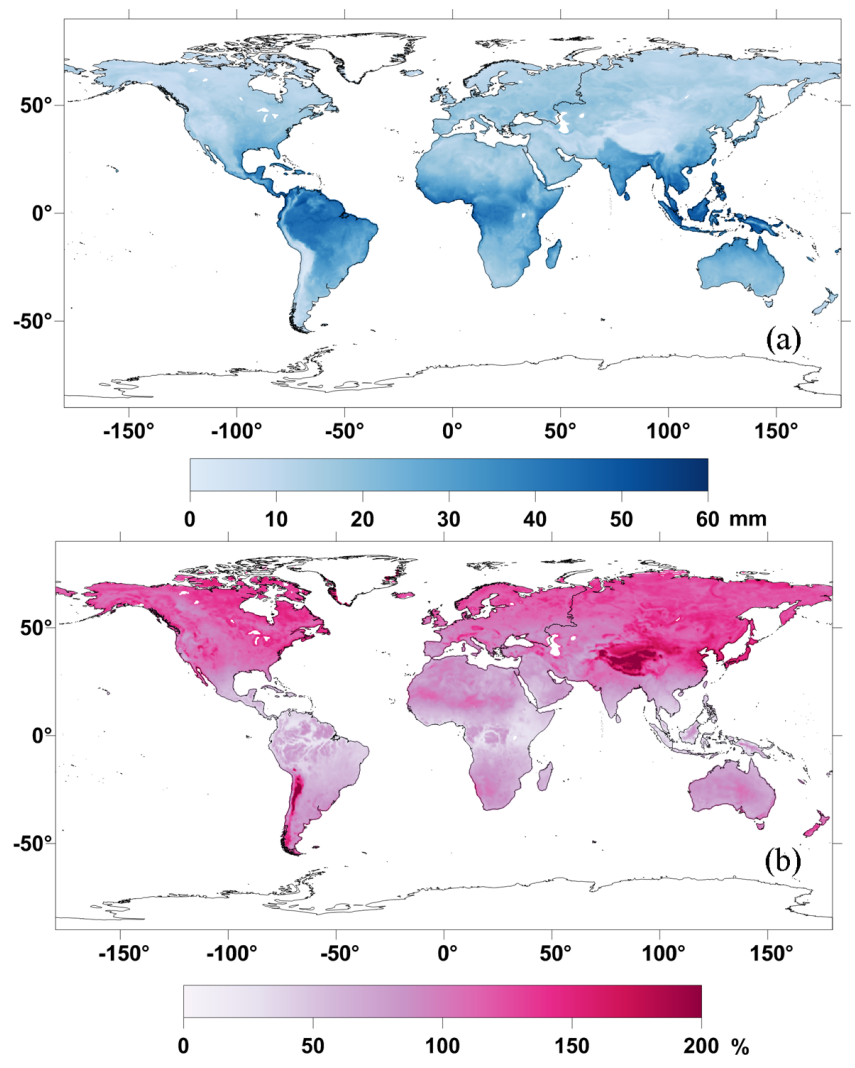

Figure 4. LPDR PWV climatology mean (a) and 2 times the coefficient of variation (b) from the combined 2003-2010 and 2013-2015 record.

\subsection{Atmosphere precipitable water vapor}

The spatial distributions of LPDR PWV climatology mean (Fig. 4a) and CV (Fig. 4b) results derived from ascendingorbit $T_{\mathrm{b}}$ retrievals and full-year observations were compared with benchmark satellite PWV retrievals from AIRS (Fig. S2). Both LPDR and AIRS PWV retrievals show similar global patterns and latitudinal distributions, with generally higher water vapor levels at lower latitudes and warmer

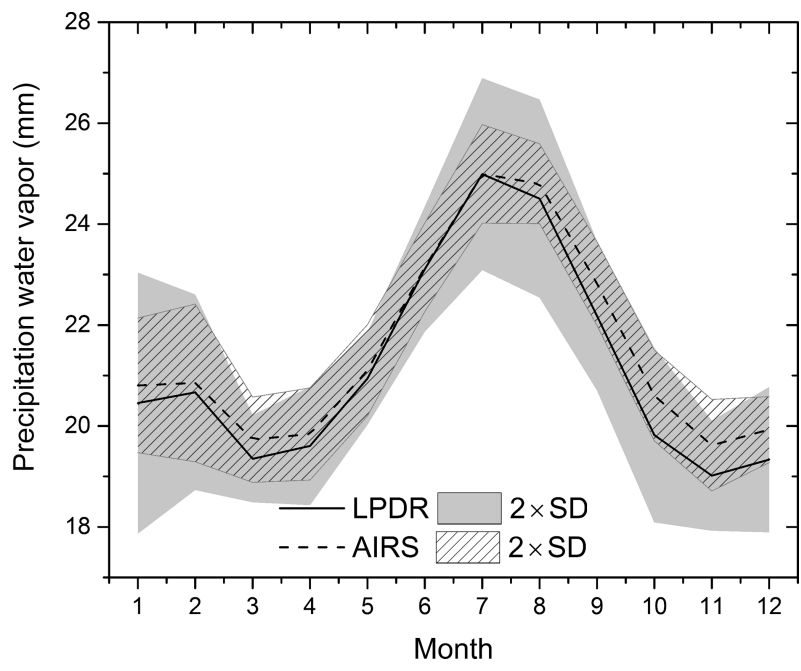

Figure 5. LPDR and AIRS PWV monthly means and seasonal variability ( 2 times the standard deviation or $2 \times \mathrm{SD}$ ) over the globe and combined for the 2003-2010 and 2013-2015 period.

climate zones, which is consistent with the near-exponential relationship between atmospheric temperature and moistureholding capacity except for dry desert regions distinguished by lower characteristic PWV levels. Especially large PWV levels are observed over the Bay of Bengal and adjacent regions (Fig. 4a) where a large amount of water vapor is transported by the summer monsoon (Uma et al., 2014). Large PWV seasonal variations (CV) are apparent in regions with distinct dry and wet seasons, including the Indian subcontinent, eastern China, and the African Sahel (Fig. 4b); these spatial and temporal patterns are consistent between the LPDR and AIRS products. The LPDR shows larger PWV seasonal variability in tropical rainforest regions (Fig. 4b) than the AIRS observations, which is attributed to ill-conditioned LPDR retrievals associated with microwave signal saturation over dense vegetation cover. Relatively large CV values in regions with average dry-air conditions (e.g., the Tibetan Plateau) reflect the strong sensitivity of the $\mathrm{CV}$ metric to small mean humidity values in the denominator ( $\% \mathrm{CV}=100 \cdot \mathrm{SD} /$ mean). Overall, the LPDR and AIRS ascending- and descending-orbit-derived PWV monthly means are highly correlated $(R=0.99)$ (Fig. 5) with a major peak in the Northern Hemisphere summer months (July and August) and a secondary peak in the Southern Hemisphere summer months (January and February).

The LPDR PWV retrievals were quantitatively validated against the AIRS observations at 142 global WMO weather station locations for the years 2010 and 2013 (Table 2). The AMSR-E/2 retrievals show strong agreement with the AIRS PWV product $(R \geq 0.91 ; \mathrm{RMSE} \leq 4.94 \mathrm{~mm})$, though a slight PWV overestimation and underestimation are indicated for the respective AMSR-E (bias $\leq 0.27 \mathrm{~mm}$ ) and AMSR2 (bias $\geq-0.37 \mathrm{~mm}$ ) portions of the record (Table 2). 
Table 2. LPDR daily $T_{\mathrm{mn}}, T_{\mathrm{mx}}$, and ascending- or descending-orbit-based PWV accuracy in relation to respective in situ air temperature measurements and AIRS PWV observations for 142 global WMO site locations for the selected years 2010 (AMSR-E) and 2013 (AMSR2).

\begin{tabular}{|c|c|c|c|c|c|c|}
\hline & \multicolumn{3}{|c|}{$T_{\mathrm{mx}}\left({ }^{\circ} \mathrm{C}\right)$} & \multicolumn{3}{|c|}{$T_{\mathrm{mn}}\left({ }^{\circ} \mathrm{C}\right)$} \\
\hline & $R$ & RMSE & Bias* & $R$ & RMSE & Bias \\
\hline AMSR-E & 0.928 & 3.428 & 0.637 & 0.899 & 3.307 & 0.061 \\
\hline \multirow[t]{3}{*}{ AMSR2 } & 0.917 & 3.484 & 0.260 & 0.899 & 3.150 & 0.265 \\
\hline & \multicolumn{3}{|c|}{$\begin{array}{l}\text { PWV }(\mathrm{mm}) \text { from } \\
\text { ascending orbits }\end{array}$} & \multicolumn{3}{|c|}{$\begin{array}{l}\text { PWV }(\mathrm{mm}) \text { from } \\
\text { descending orbits }\end{array}$} \\
\hline & $R$ & RMSE & Bias & $R$ & RMSE & Bias \\
\hline AMSR-E & 0.926 & 4.241 & 0.2 & 0.923 & 4.788 & 0.197 \\
\hline AMSR2 & 0.914 & 4.473 & -0.369 & 0.911 & 4.941 & -0.050 \\
\hline
\end{tabular}

* Bias is calculated from retrievals minus observations.

\subsection{Daily maximum and minimum surface air temperature}

The LPDR-derived global mean and CV variability maps for $T_{\mathrm{mx}}$ are presented in Fig. 6, while the $T_{\mathrm{mn}}$ results show similar global and seasonal patterns. The LPDR results show characteristic global temperature patterns following major climate zones and latitudinal gradients and are similar to the PWV results (Fig. 4) but with generally greater surface spatial complexity influenced by proximity to coastal areas, vegetation and land cover conditions, and elevation-driven temperature lapse rates (Du et al., 2015). The LPDR results show expected smaller seasonal temperature variability (CV) near the Equator and larger variability at higher latitudes, especially in the interior of large landmasses such as North America and Asia. The resulting temperature maps (Fig. 6) only represent nonfrozen land surface conditions rather than complete annual cycles (i.e., Sects. 2.3, 3.1). We also note that the LPDR surface air temperatures are derived from ascendingand descending-orbit $T_{\mathrm{b}}$ retrievals empirically adjusted to represent daily $T_{\mathrm{mx}}$ and $T_{\mathrm{mn}}$ conditions using in situ temperature measurements from sparse global weather stations. Thus the LPDR results may deviate from actual daily maximum and minimum temperature conditions for some areas and periods; these and other uncertainties impact LPDR accuracy and performance, which are evaluated in the following temperature assessment.

The LPDR-derived $T_{\mathrm{mx}}$ and $T_{\mathrm{mn}}$ retrievals were validated against independent in situ daily air temperature measurements from 142 global WMO weather stations for the years 2010 and 2013 (Table 2). Overall, the LPDR temperatures corresponded favorably with the WMO temperature measurements $\left(R \geq 0.90 ; \mathrm{RMSE} \leq 3.48^{\circ} \mathrm{C}\right)$. The AMSRE (2010) and AMSR2 (2013) retrievals show similar $T_{\mathrm{mx}}$ and $T_{\mathrm{mn}}$ retrieval accuracy, with associated RMSE differences within $0.16 \mathrm{~K}$ in relation to the WMO daily temperature measurements. These results indicate improved LPDR temperature accuracy relative to previously reported
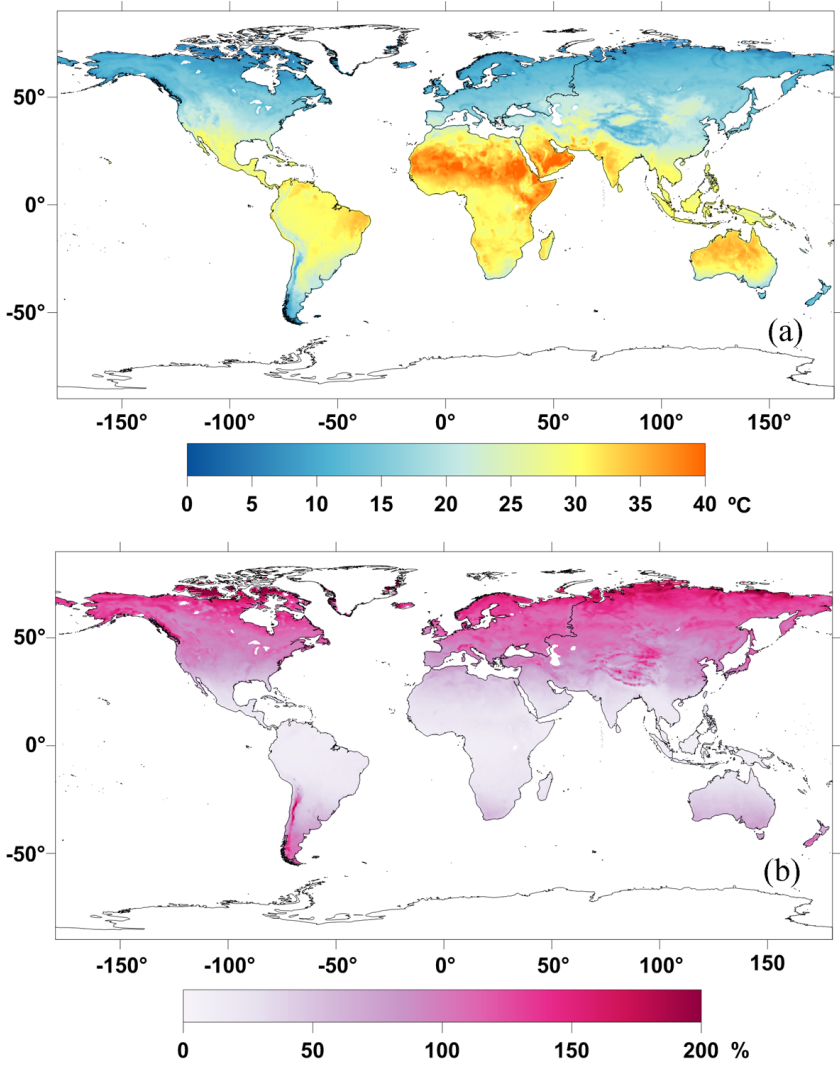

Figure 6. LPDR $T_{\mathrm{mx}}$ mean (a) and 2 times the coefficient of variation (b) for the years 2003-2010 and 2013-2015.

AMSR2-derived accuracies for $T_{\mathrm{mx}}\left(\mathrm{RMSE}=3.64^{\circ} \mathrm{C}\right)$ and $T_{\mathrm{mn}}\left(\mathrm{RMSE}=3.54^{\circ} \mathrm{C}\right.$ ) from a prior study (Du et al., 2014); the higher LPDR temperature accuracy (RMSE $\leq 3.48^{\circ} \mathrm{C}$ ) suggests an improvement in sensor inter-calibration and algorithm refinements (Sect. 3.1). However, the calibrated AMSR2 $T_{\mathrm{b}}$ is not identical to that of AMSR-E as reflected by a maximum $0.38^{\circ} \mathrm{C}$ difference in their $T_{\mathrm{mx}}$ and $T_{\mathrm{mn}}$ retrieval 
biases against WMO measurements (Table 2). To evaluate the impact of the fractional water corrections on the LPDR v2 air temperature retrievals, Eqs. (1)-(4) were re-derived using the same procedure (Sect. 2.2) but assuming zero fractional water cover. The results indicated approximately $13 \%$ improved RMSE performance in the $T_{\mathrm{mx}}$ and $T_{\mathrm{mn}}$ retrievals using the $\mathrm{FW}$ correction relative to air temperature retrievals derived without accounting for fractional water influence.

\subsection{Vegetation optical depth}

The previous UMT LPDR v1 AMSR-E VOD record was assessed globally (Jones et al., 2011) and has been used for a range of regional ecosystem studies, including vegetation phenology and disturbance recovery assessments (Liu et al., 2013; Jones et al., 2013, 2014). The VOD record can also be used as a data quality mask for the VSM retrievals because soil moisture retrieval accuracy is generally degraded under higher vegetation biomass levels (Du et al., 2016a). In this study, the LPDR-derived VOD was compared with the GIMMS3g NDVI record based on an assumption of proportionality between vegetation canopy biomass and greenness variations (Jones et al., 2011). The evaluation results of the previous and current studies are consistent, including generally favorable correlations between VOD and optical vegetation indices and reduced correspondence at higher biomass levels.

The LPDR VOD pattern and seasonal variability $(\mathrm{CV})$ are generally consistent with the global pattern in vegetation cover indicated from the NDVI record (Fig. S3).The LPDRderived mean annual VOD results (Fig. 7a) show characteristic global patterns in vegetation biomass, including higher VOD in tropical rainforests (e.g., the Amazon Basin, the Congo Basin, and Southeast Asia) and much lower VOD in arid and sparsely vegetated areas, including the Sahara and Sonoran deserts and Central Australia. Moderate VOD levels occur in grassland, shrubland, and cropland areas, including the central USA, sub-Saharan Africa, central China, and India. Larger VOD relative seasonal variability (Fig. 7b) occurs over predominantly deciduous and lower biomass areas, including grassland, shrubland, and cropland. Large VOD seasonal variations also occur in semiarid climate zones with distinctive wet and dry cycles, including the African Sahel where plant growth depends on seasonal rainfall (Proud and Rasmussen, 2011). A few VOD change hotspots occur in wetland areas (e.g., the Iberá Wetlands in Argentina and the Bangweulu Wetlands in Zambia), which may reflect emergent vegetation overlying a standing water background during the wet season. Lower VOD seasonality occurs in the tropics, which is consistent with a smaller seasonal climate cycle near the equatorial zone. Arid areas show the generally low VOD levels and seasonality consistent with sparse vegetation cover except for some areas, including portions of the Arabian Peninsula, where relatively large VOD seasonality may be a result of irrigation activities (Siebert et al., 2005).

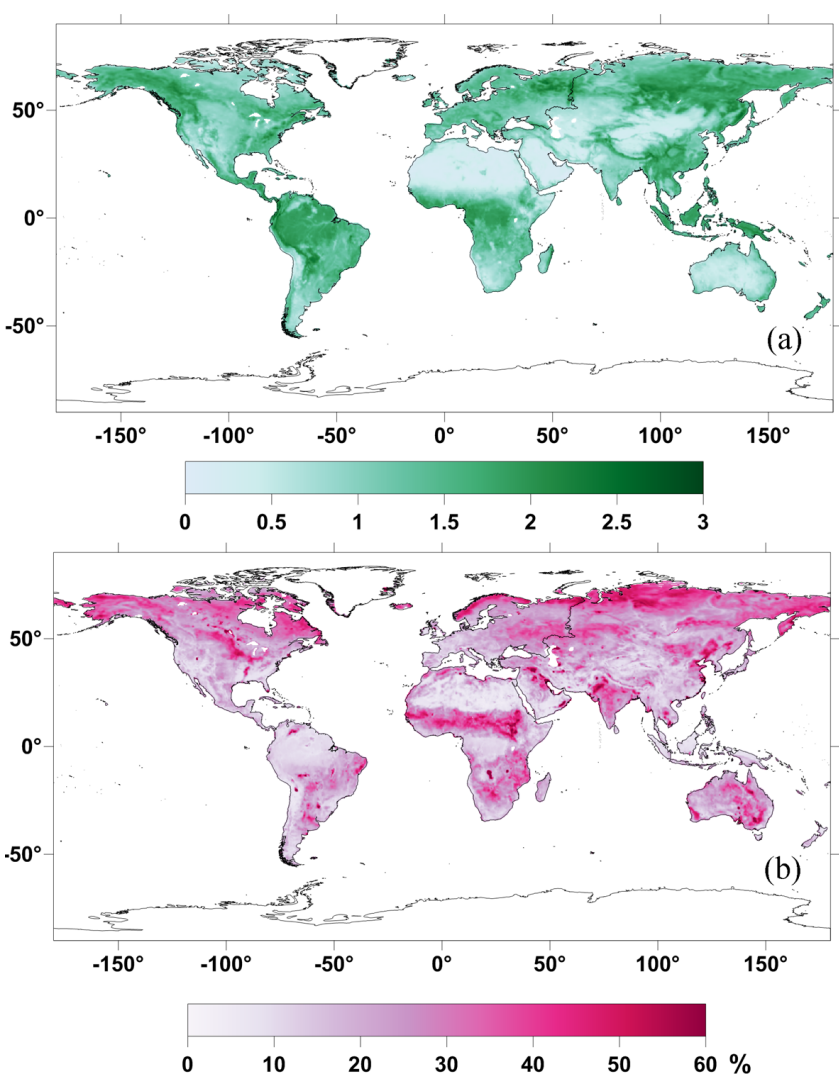

Figure 7. Annual mean (a) and 2 times the coefficient of variation (b) of LPDR $25 \mathrm{~km}$ global X-band VOD daily estimates from AMSR-E/2 ascending observations encompassing the years 2003 2010 and 2013-2015.

Both VOD and NDVI display similar seasonal cycles represented by their mean monthly time series $(R \geq 0.88)$ but with temporal phase offsets in VOD and NDVI cycles for different land cover types (Fig. 8). Here, the mean seasonal cycle in VOD and NDVI is depicted for major IGBP global land cover types, including evergreen needleleaf forest (ENF), evergreen broadleaf forest (EBF), deciduous needleleaf forest (DNF), deciduous broadleaf forest (DBF), grassland, and cropland. The LPDR VOD and GIMMS3g NDVI comparison results are summarized in Table 3 and show strong correspondence for both ascending-orbit $(0.67 \leq R \leq 0.90)$ and descending-orbit $(0.84 \leq R \leq 0.95)$ retrievals for ENF, DNF, grassland, and cropland areas with relatively welldefined seasonal cycles. A VOD temporal phase shift relative to NDVI is evident for croplands and detectable for other land cover types, reflecting different vegetation biophysical properties that the microwave and optical-infrared instruments are sensitive to (Jones et al., 2011, 2012). Weaker and even negative VOD and NDVI correlations in EBF regions coincide with lower characteristic canopy seasonality in the tropics, but may reflect degraded signal-to-noise ratios due to persistent cloud and atmospheric aerosol effects limiting effective NDVI retrievals and VOD and NDVI sat- 
Table 3. Pearson correlations $(R)$ between LPDR VOD and GIMMS3g NDVI climatology monthly means for the aggregate 2003-2010 and 2013-2015 observation record. The comparisons were made for all global vegetation and selected land cover areas, including ENF, EBF, DNF, DBF, grassland, and cropland. Both products were projected into a consistent $25.0 \mathrm{~km}$ resolution EASE-Grid format. VOD results are delineated for LPDR ascending- and descending-orbit records.

\begin{tabular}{lrrrrrrr}
\hline $\begin{array}{l}\text { Pearson correlation } \\
\text { coefficient }\end{array}$ & Global & ENF & EBF & DNF & DBF & Grassland & Cropland \\
\hline Ascending & 0.878 & 0.715 & 0.218 & 0.893 & 0.201 & 0.903 & 0.665 \\
Descending & 0.937 & 0.898 & -0.116 & 0.944 & 0.871 & 0.951 & 0.845 \\
\hline
\end{tabular}
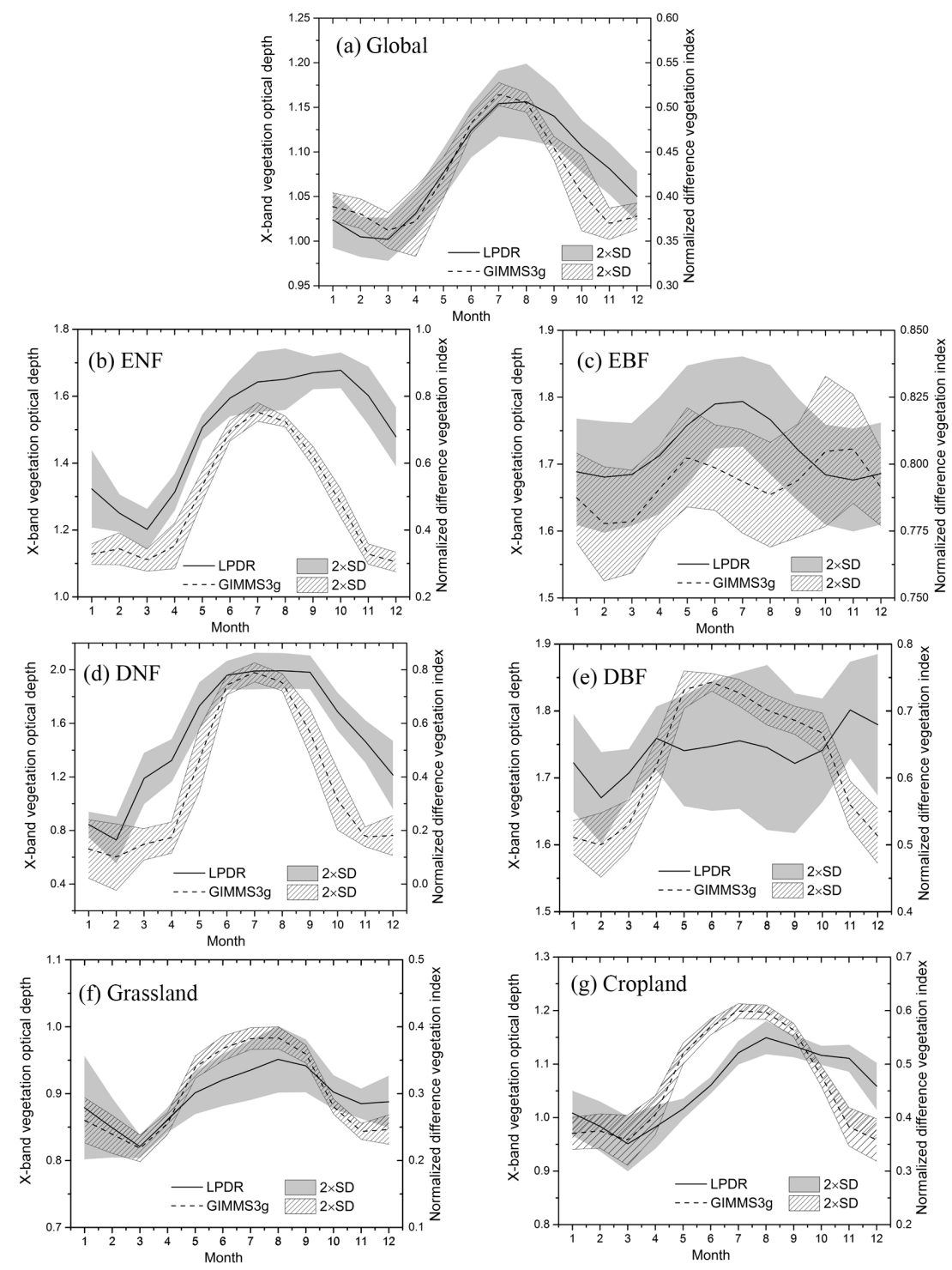

Figure 8. Monthly means and variations $(2 \times \mathrm{SD})$ of LPDR X-band vegetation optical depth (VOD) and GIMMS3g NDVI for all global vegetation (a) and selected land cover types, including ENF (b), EBF (c), DNF (d), DBF (e), grassland (f), and cropland (g) areas over the aggregate 2003-2010 and 2013-2015 observation period.

uration over dense canopies (Jones et al., 2011). For dense canopies, NDVI seasonality can be strongly driven by the onset of new leaves flushing (E. E. Maeda et al., 2016), while the asynchrony between leaf flush and vegetation growth may also affect the VOD and NDVI correlations (Jones et al., 2014). The VOD estimates derived from the descending- 

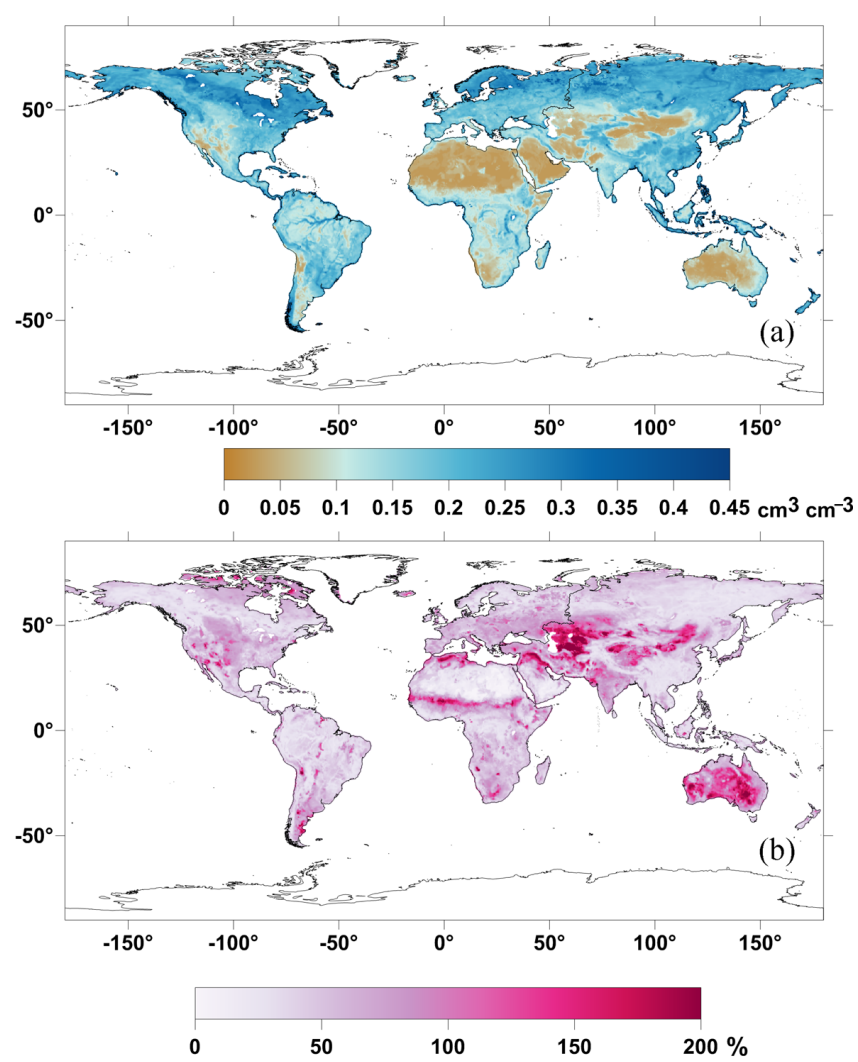

Figure 9. LPDR $25 \mathrm{~km}$ X-band volumetric soil moisture (VSM) mean (a) and 2 times the coefficient of variation in percentage of mean values (b) derived from the aggregate 2003-2010 and 20132015 observation record.

orbit $T_{\mathrm{b}}$ retrievals also show overall stronger correspondence with NDVI than the ascending retrievals, especially for DBF regions (descending orbit $R=0.87$; ascending orbit $R=0.20$ ). Differences in NDVI correspondence between the ascending- and descending-orbit VOD records may reflect regional VOD retrieval uncertainties contributed by deficiencies in the underlying LPDR algorithm assumptions and parameterizations, which are discussed below (Sect. 5).

\subsection{Soil moisture}

The global soil moisture pattern depicted by the LPDR Xband VSM record (Fig. 9) is generally consistent with the known global climatology, including characteristically wet surface soil moisture conditions in northern high-latitude areas and drier soil moisture extremes in deserts and semiarid regions such as the African Sahara, the southwestern USA, and Central Australia. Wetter VSM conditions along coastal boundaries may reflect remaining ocean $T_{\mathrm{b}}$ contamination of adjacent land grid cells within the coarser sensor footprint despite explicit FW correction of the VSM retrievals. Relatively large seasonal soil moisture variations are associated with areas having distinctive wet and dry seasons, includ- ing the African Sahel, Central USA, the Indian subcontinent, and southern Tibet. For arid regions such as Central Australia, high relative (\%) seasonal CV variability is due to low average VSM conditions. Lower VSM variability occurs over higher vegetation biomass (VOD) areas, including forests, where AMSR-E/2 soil moisture sensitivity and VSM retrieval performance are expected to be lower due to loss of soil sensitivity; the global range of effective VSM retrievals and other LPDR observations is represented by the data quality metrics described below (Sect. 5.2).

The LPDR VSM retrievals were compared against globally distributed validation watershed measurements (Table 4). The LPDR results show overall favorable VSM accuracy in relation to independent in situ soil moisture observations from the globally distributed monitoring sites within the effective LPDR domain $(0.63 \leq R \leq 0.84 ; 0.03 \leq$ biascorrected RMSE $\left.\leq 0.06 \mathrm{~cm}^{3} \mathrm{~cm}^{-3}\right)$. The apparent retrieval biases ( -0.10 to 0.09 ) may partially reflect inconsistencies in horizontal and vertical representativeness between the in situ soil moisture measurements and AMSR-E/2 $T_{\mathrm{b}}$ retrievals (Du et al., 2016a). These results indicate similar or better accuracy than the reported performance of other AMSR-E soil moisture products (Jackson et al., 2010; Du et al., 2016a) and generally better LPDR performance for descending-orbit (AM) than ascending-orbit (PM) VSM retrievals.

\section{Discussion}

The latest (v2) LPDR incorporates recent algorithm refinements and updates over the original baseline algorithms and data record (Jones et al., 2010) while also including an extended global data record spanning both AMSR-E and AMSR2 observation periods (June 2002-December 2015). The resulting data record produces global environmental patterns and seasonal dynamics consistent with characteristic climate and land cover variability; the LPDR also shows favorable agreement with a diverse set of independent observation benchmarks. The LPDR algorithms and parameter estimates are internally consistent and include an integrated set of environmental parameters representing atmosphere, vegetation, surface, and soil conditions derived from simultaneous satellite multifrequency $T_{\mathrm{b}}$ observations. The iterative algorithm and multiparameter retrieval approach enable the decomposition of the satellite observations into atmosphere, vegetation, standing water, and soil moisture components. In particular, the dynamic open water (FW) correction in the LPDR algorithm benefits VSM retrievals over areas with significant spatial and seasonal inundation variability. The current algorithm is limited to nonfrozen land surface conditions determined using an independent AMSR-E/2 FT product (Kim et al., 2017), while the FT parameter is represented as a simplified daily frozen flag in the LPDR. Potential extension of the LPDR to represent snow cover properties and frozen conditions would enable continuous land 
Table 4. Summary of satellite LPDR soil moisture retrieval accuracy in relation to in situ surface soil moisture measurements from four globally distributed validation watersheds.

\begin{tabular}{lrrrrr}
\hline Statistics & $\begin{array}{r}\text { Little River } \\
\text { (USA; 2003-2005) }\end{array}$ & $\begin{array}{r}\text { Little Washita } \\
\text { (USA; 2003-2005) }\end{array}$ & $\begin{array}{r}\text { Nagqu } \\
\text { (China; 2010-2011) }\end{array}$ & $\begin{array}{r}\text { Yanco } \\
\text { (Australia; 2009-2010) }\end{array}$ \\
\hline \multicolumn{7}{c}{ Ascending orbits sites } \\
\hline$R$ & 0.627 & 0.762 & 0.790 & 0.755 & 0.815 \\
RMSE & 0.035 & 0.036 & 0.051 & 0.059 & 0.045 \\
Bias & 0.041 & 0.053 & -0.102 & -0.042 & 0.012 \\
\hline \multicolumn{7}{c}{} \\
\hline$R$ & 0.696 & 0 Descending orbits \\
RMSE & 0.032 & 0.733 & 0.831 & 0.787 & 0.835 \\
Bias & 0.071 & 0.036 & 0.042 & 0.055 & 0.042 \\
& 0.086 & -0.063 & -0.031 & 0.038 \\
\hline
\end{tabular}

$R$ is correlation coefficient; RMSE (root mean square error) and bias are in $\mathrm{cm}^{3} \mathrm{~cm}^{-3}$. RMSE and all site statistics except bias are calculated with watershed bias corrected.

parameter observations over a full annual cycle while incorporating observations of other key environmental indicators of the changing cryosphere. The complex microwave emission and scattering signatures of snow, lake ice, frozen soil, and vegetation must first be carefully accounted for to enable the further development and extension of the LPDR retrieval algorithms (Tedesco et al., 2010; Du et al., 2017).

\subsection{LPDR data format}

The resulting LPDR is available in a $25 \mathrm{~km}$ resolution global EASE-Grid (v1) projection and GeoTIFF file format. The data files are organized by ascending and descending orbits on a daily basis. Each GeoTIFF file consists of six 2-D (1383 columns, 586 rows) data arrays representing five float-type retrieval data bands (FW, $T_{\mathrm{mx}}$ or $\left.T_{\mathrm{mn}}, T_{\mathrm{c}}, \mathrm{PWV}, \mathrm{VSM}\right)$ and one byte-type QC band. A set of product QC flags are included to inform the user about the estimated quality of retrieved parameters or missing data. The QC binary bit flags are summarized in Table 5 and indicate the presence or absence of the following land surface conditions: frozen ground (bit 1), snow or ice presence (bit 2), strong precipitation (bit 3), RFI at $18.7 \mathrm{GHz}$ (bit 4), RFI at $10.65 \mathrm{GHz}$ (bit 5), dense vegetation with $\operatorname{VOD}>2.3$ (bit 6 ), large water bodies with FW $>0.2$ (bit 7), and saturated microwave signals (difference between V-pol and H-pol brightness temperature at 18 or $23 \mathrm{GHz}$ less than $1.0 \mathrm{~K}$; bit 8). The percentages of land areas with high QC retrievals were summarized by seasons and sensor orbits (Table 6).

\subsection{Data record consistency}

The LPDR record described in this study extends from June 2002 to December 2015 and captures both short-term (diurnal, daily, annual) variability and longer-term (annual, decadal) climate trends over the global terrestrial environment for a diverse set of significant environmental param-

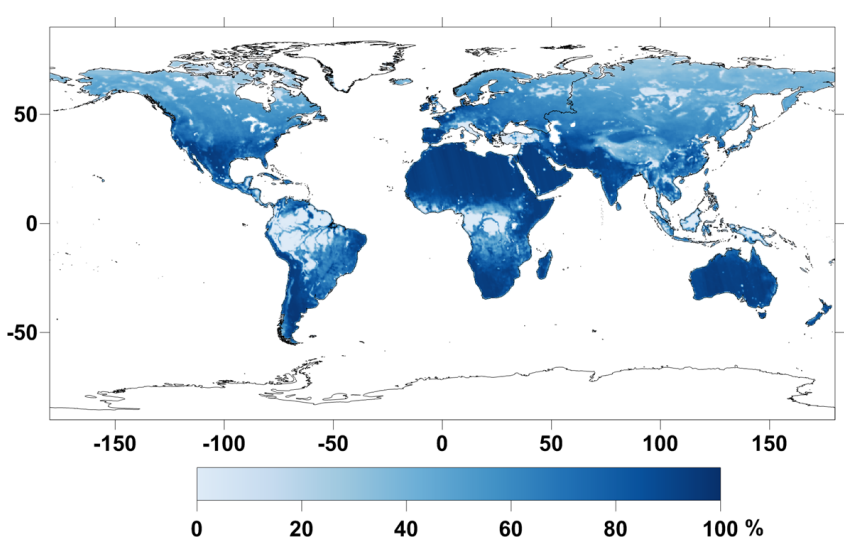

Figure 10. Temporal frequency distribution map of estimated highquality (QC) retrievals, which exclude areas with dense vegetation (VOD > 2.3), saturated microwave signals (V-pol and H-pol $T_{\mathrm{b}}$ difference at 18 or $23 \mathrm{GHz}$ less than $1.0 \mathrm{~K}$ ), and large water bodies $(\mathrm{FW}>0.2)$.

eters. Potential differences in $T_{\mathrm{b}}$ characteristics and algorithm performance between the AMSR-E and AMSR2 portions of the LPDR are expected to introduce artifacts and degrade LPDR precision for analyzing long-term environmental changes. LPDR data consistency was examined through statistical comparison of best-quality (QC) retrievals between the AMSR-E and AMSR2 portions of the record (Sect. 2.3); the global pattern and temporal frequency of the estimated best retrievals are presented in Fig. 10. As summarized in Table S1 in the Supplement, the land parameter retrievals have similar mean values, variations, and ranges between the AMSR-E and AMSR2 portions of the record, indicating general LPDR consistency and quality. However, the underlying $T_{\mathrm{b}}$ retrieval biases between the two sensors are not completely removed by the sensor intercalibration process (Du et al., 2014), which may propagate to uncertainty in the higher-order LPDR retrievals and 
Table 5. LPDR data quality flag description.

\begin{tabular}{lll}
\hline Bit number & Land surface condition & Indication \\
\hline 1 & Frozen ground & No LPDR retrieval \\
2 & Snow or ice presence & No LPDR retrieval \\
3 & Strong precipitation & No LPDR retrieval \\
4 & RFI at $18.7 \mathrm{GHz}$ & No LPDR retrieval \\
5 & RFI at $10.65 \mathrm{GHz}$ & No LPDR retrieval \\
6 & Dense vegetation with VOD $>2.3$ & Possible large retrieval uncertainty \\
7 & Large water bodies with FW $>0.2$ & Possible large retrieval uncertainty \\
8 & Saturated microwave signals with V-pol and H-pol $T_{\mathrm{b}}$ & Possible large retrieval uncertainty \\
& difference at 18 or $23 \mathrm{GHz}$ less than $1.0 \mathrm{~K}$ & \\
\hline
\end{tabular}

Table 6. The percentages of land areas having high QC retrievals summarized by seasons and sensor orbits; seasons aggregated by spring (MAM), summer (JJA), autumn (SON), and winter (DJF) months of the Northern Hemisphere.

\begin{tabular}{lccccc}
\hline & \multicolumn{2}{c}{ Ascending } & & \multicolumn{2}{c}{ Descending } \\
\cline { 2 - 3 } \cline { 5 - 6 } & $\begin{array}{c}\text { Northern } \\
\text { Hemisphere }\end{array}$ & $\begin{array}{c}\text { Southern } \\
\text { Hemisphere }\end{array}$ & & $\begin{array}{c}\text { Northern } \\
\text { Hemisphere }\end{array}$ & $\begin{array}{c}\text { Southern } \\
\text { Hemisphere }\end{array}$ \\
\hline MAM & $95.8 \%$ & $92.6 \%$ & & $93.1 \%$ & $88.4 \%$ \\
JJA & $95.3 \%$ & $92.6 \%$ & & $94.4 \%$ & $89.2 \%$ \\
SON & $95.1 \%$ & $93.5 \%$ & & $93.4 \%$ & $89.2 \%$ \\
DJF & $76.5 \%$ & $92.2 \%$ & & $73.0 \%$ & $88.3 \%$ \\
\hline
\end{tabular}

trends. For ascending retrievals, the AMSR2 biases relative to AMSR-E for the LPDR parameters FW, PWV, $T_{\mathrm{mx}}$, VOD, and VSM are about $0.00,-0.50 \mathrm{~mm},-0.24^{\circ} \mathrm{C},-0.03$, and $-0.01 \mathrm{~cm}^{3} \mathrm{~cm}^{-3}$, respectively. For descending retrievals, the corresponding biases are $0.00,-0.45 \mathrm{~mm}, 0.13^{\circ} \mathrm{C}, 0.01$, and $0.01 \mathrm{~cm}^{3} \mathrm{~cm}^{-3}$. The AMSR2 record also tends to have smaller PWV- and VOD-derived SD variability and ranges compared with AMSR-E (Table S1). Similar differences between AMSR-E and AMSR2 retrievals are also evident in the validation assessments against the independent observations, including WMO surface air temperature measurements and AIRS PWV (Table 2).

\subsection{LPDR uncertainty}

While the v2 data record provides new refinements and enhancements over the earlier LPDR baseline, several product uncertainty and consistency issues remain unresolved. The LPDR VOD and VSM analysis (Sect. 4.4 and 4.5) indicated generally better performance for descending- than ascending-orbit retrievals. Better descending $(\sim 01: 30)$ performance may result from seasonal changes in thermal gradients between surface air, canopy, and ground layer conditions through the process of leaf development (Durre and Wallace, 2001), which is not accounted for in the VOD retrieval algorithm (Jones et al., 2012). The AMSR-E/2 descending observations reflect relatively isothermal early morning conditions that promote better VOD and VSM performance relative to ascending observations under midday $(\sim 13: 30)$ conditions characterized by larger thermal gradients.

The LPDR retrievals in more densely vegetated areas (e.g., VOD > 2.3) are expected to have greater uncertainty and should be used with caution; these areas are flagged in the LPDR QC data fields and distinguished from areas with expected higher-quality retrievals (Fig. 10). In more densely vegetated areas, the higher-frequency AMSR-E/2 $T_{\mathrm{b}}$ retrievals are more likely to have smaller polarization differences and signal saturation, resulting in less sensitivity to VOD and PWV and higher retrieval uncertainties. For this reason, differences in VOD and PWV retrievals between AMSR-E and AMSR2 may be magnified over more densely vegetated areas where sensor inter-calibration uncertainties further lower the signal-to-noise ratio. Denser vegetation cover also promotes stronger attenuation of underlying soil and water microwave signals, increasing VSM retrieval uncertainty in these areas (Du et al., 2016a). Similarly, the retrieval accuracy for standing water with overlying vegetation cover, a different scenario from the exposed open water with surrounding vegetation cover assumed in this study, is expected to decrease exponentially under higher VOD levels (Du et al., 2016b). The land parameter grid cells and retrievals along coastlines and other large water bodies are likely to be affected by water contamination of the coarse sensor $T_{\mathrm{b}}$ footprint, though these effects are partially accounted for by representation of FW on the associated land parameter retrievals within a grid cell. Regions with larger FW cover may have higher retrieval uncertainties, which are represented as a water flag $(\mathrm{FW}>0.2)$ in the LPDR quality mask (Fig. 10).

The AMSR2 and AMSR-E $T_{\mathrm{b}}$ records used for this study were previously calibrated (Du et al., 2014), but remaining artifacts from the different sensor spatial resolutions and instrument calibration systems likely contribute to differences in land parameter characteristics and performance between the two sensor periods of the record. Though small in quantity, the AMSR2 retrieval biases relative to AMSR-E (Tables 2 and S1) should be considered when analyzing longterm environmental trends. Differences in parameter accu- 
racy and performance between AMSR2 and AMSR-E observations and a limited (12.5 years) LPDR (v2) period of record constrain capabilities for assessing subtle environmental trends. Future LPDR releases are expected to benefit from continuing AMSR2 operations and calibration refinements to the integrated AMSR-E/ $2 T_{\mathrm{b}}$ record, enabling more accurate environmental change assessments.

\section{Data availability}

The AMSR-E/2-derived LPDR described in this study is publicly available through the following link: http://files. ntsg.umt.edu/data/LPDR_v2.

\section{Conclusions}

We developed an extended global land parameter data record for ecosystem studies using similar calibrated satellite multifrequency and polarization $T_{\mathrm{b}}$ retrievals from AMSR-E and AMSR2. The latest (v2) LPDR represents an advance over a prior (v1) product release by incorporating recent algorithm refinements and an extended (June 2002-December 2015) satellite observation record. The LPDR algorithms are internally consistent and rely on AMSR-E and AMSR2 brightness temperatures as primary inputs. The algorithms exploit the strong microwave sensitivity to liquid water in the landscape and the variable sensitivity of different $T_{\mathrm{b}}$ frequencies and polarizations to vegetation, soil, and atmosphere elements to derive a set of synergistic daily land parameters, including VSM, FW, VOD, $T_{\mathrm{mx}}, T_{\mathrm{mn}}$, and PWV. The resulting data record shows favorable accuracy and performance in relation to a diversity of other observation benchmarks. However, small but significant differences were found between the AMSR-E and AMSR2 portions of the record due to artifacts from cross-sensor calibration; these effects should be considered when interpreting environmental trends from the long-term record. The LPDR provides global coverage and up to twice-daily observations for non-snow- or non-icecovered land surface conditions. The data are publicly available with detailed documentation and data quality information and with suitable precision to support a range of environmental studies. Example LPDR applications from the literature include land surface phenology monitoring, vectorborne disease risk, surface hydrology and drought severity, and climate-change-related assessments. Continuing operations from AMSR2 and similar microwave sensors allow for future LPDR extensions, while further calibration refinements and a longer data record are expected to yield additional gains in precision and product utility for distinguishing and diagnosing global environmental changes.

\section{The Supplement related to this article is available online at https://doi.org/10.5194/essd-9-791-2017-supplement.}

Competing interests. The authors declare that they have no conflict of interest.

Acknowledgements. AMSR-E data are produced by Remote Sensing Systems and sponsored by the NASA Earth Science MEaSUREs DISCOVER Project and the AMSR-E Science Team. Data are available at www.remss.com. AMSR-E data and land cover classification maps were also provided courtesy of the National Snow and Ice Data Center (NSIDC). The AMSR2 L1R data used for this study were provided courtesy of JAXA. This work was conducted at the University of Montana with funding from NASA (NNX14AB20A, NNX15AT74A, NNX15AB59G).

Edited by: Michael E. Contadakis

Reviewed by: two anonymous referees

\section{References}

Alemu, W. G. and Henebry, G. M.: Land surface phenologies and seasonalities using cool earthlight in mid-latitude croplands, Environ. Res. Lett., 8, 045002, https://doi.org/10.1088/17489326/8/4/045002, 2013.

Armstrong, R. L. and Brodzik, M. J.: An earth-gridded SSM/I data set for cryospheric studies and global change monitoring, Adv. Space Res., 16, 155-163, 1995.

Ashcroft, P. and Wentz, F.: Algorithm Theoretical Basis Document, AMSR Level 2A Algorithm, Santa Rosa, CA, RSS Tech. Rep. 121 599B-1, 1999.

Bedka, S., Knuteson, R., Revercomb, H., Tobin, D., and Turner, D.: An assessment of the absolute accuracy of the Atmospheric Infrared Sounder v5 precipitable water vapor product at tropical, midlatitude, and arctic ground-truth sites: September 2002 through August 2008, J. Geophys. Res., 115, D17310, https://doi.org/10.1029/2009JD013139, 2010.

Brodzik, M. J. and Knowles, K. W.: EASE-Grid: A versatile set of equal area projections and grids, in: Discrete Global Grids, edited by: Goodchild, M., National Center for Geographic Information \& Analysis, Santa Barbara, CA, 2002.

Brouwer, R., Akter, S., and Brander, L.: Socioeconomic vulnerability and adaptation to environmental risk: a case study of climate change and flooding in Bangladesh, Risk Anal., 27, 313-326, 2007.

Carroll, M., Townshend, J., DiMiceli, C., Noojipady, P., and Sohlberg, R.: A New Global Raster Water Mask at $250 \mathrm{~m}$ Resolution, International Journal of Digital Earth, 2, 291-308, 2009.

Chen, Y., Yang, K., Qin, J., Zhao, L., Tang, W., and Han, M.: Evaluation of AMSR-E retrievals and GLDAS simulations against observations of a soil moisture network on the central Tibetan plateau, J. Geophys. Res.-Atmos., 118, 4466-4475, https://doi.org/10.1002/jgrd.50301, 2013.

Chuang, T. W., Henebry, G. M., Kimball, J. S., VanRoekel-Patton, D. L., Hildreth, M. B., and Wimberly, M. C.: Satellite microwave remote sensing for environmental modeling of mosquito population dynamics, Remote Sens. Environ., 125, 147-156, 2012.

Déry, S. J., Hernández-Henríquez, M. A., Burford, J. E., and Wood, E. F.: Observational evidence of an intensifying hydrological 
cycle in northern Canada, Geophys. Res. Lett., 36, L13402, https://doi.org/10.1029/2009GL038852, 2009.

Diao, M., Jumbam, L., Sheffield, J., Wood, E. F., and Zondlo, M. A.: Validation of AIRS/AMSU-A water vapor and temperature data with in situ aircraft observations from the surface to UT/LS from $87^{\circ} \mathrm{N}-67^{\circ} \mathrm{S}$, J. Geophys. Res.-Atmos., 118, 6816-6836, https://doi.org/10.1002/jgrd.50483, 2013.

Divakarla, M. G., Barnet, C. D., Goldberg, M. D., McMillin, L. M., Maddy, E., Wolf, W., Zhou, L., and Liu, X.: Validation of Atmospheric Infrared Sounder temperature and water vapor retrievals with matched radiosonde measurements and forecasts, J. Geophys. Res., 111, D09S15, https://doi.org/10.1029/2005JD006116, 2006.

Du, J., Kimball, J. S., Shi, J., Jones, L. A., Wu, S., Sun, R., and Yang, H.: Inter-calibration of satellite passive microwave land observations from AMSR-E and AMSR2 using overlapping FY3B-MWRI sensor measurements, Remote Sens., 6, 85948616, 2014.

Du, J., Kimball, J. S., and Jones, L. A.: Satellite microwave retrieval of total precipitable water vapor and surface air temperature over land from AMSR2, IEEE T. Geosci. Remote, 53, 2520-2531, 2015.

Du, J., Kimball, J. S., and Jones, L. A.: Passive Microwave Remote Sensing of Soil Moisture Based on Dynamic Vegetation Scattering Properties for AMSR-E, IEEE T. Geosci. Remote, 54, 597608, 2016a.

Du, J., Kimball, J. S., Jones, L. A., and Watts, J. D.: Implementation of satellite based fractional water cover indices in the pan-Arctic region using AMSR-E and MODIS, Remote Sens. Environ., 184, 469-481, 2016b.

Du, J., Kimball, J. S., Duguay, C., Kim, Y., and Watts, J. D.: Satellite microwave assessment of Northern Hemisphere lake ice phenology from 2002 to 2015, The Cryosphere, 11, 47-63, https://doi.org/10.5194/tc-11-47-2017, 2017.

Durre, I. and Wallace, J. M.: The warm season dip in diurnal temperature range over the eastern United States, J. Climate, 14, 354360, 2001.

Entekhabi, D., Njoku, E., O’Neill, P., Kellogg, K., Crow, W., Edelstein, W., Entin, J., Goodman, S., Jackson, T., Johnson, J., Kimball, J., Piepmeier, J., Koster, R., Martin, N., McDonald, K., Moghaddam, M., Moran, S., Reichle, R., Shi, J.-C., Spencer, M., Thurman, S., Tsang, L., and Van Zyl, J.: The Soil Moisture Active Passive (SMAP) Mission, P. IEEE, 98, 704-716, https://doi.org/10.1109/JPROC.2010.2043918, 2010.

Friedl, M. A., Sulla-Menashe, D., Tan, B., Schneider, A., Ramankutty, N., Sibley, A., and Huang, X.: MODIS Collection 5 global land cover: Algorithm refinements and characterization of new datasets, Remote Sens. Environ., 114, 168-182, 2010.

Grosse, G., Romanovsky, V., Jorgenson, T., Anthony, K. W., Brown, J., Overduin, P. P. and Wegener, A.: Vulnerability and feedbacks of permafrost to climate change, Eos T. Am. Geophys. Un., 92, 73-74, 2011.

Guan, K., Wood, E.F., Medvigy, D., Kimball, J., Pan, M., Caylor, K. K., Sheffield, J., Xu, X., and Jones, M. O.: Terrestrial hydrological controls on land surface phenology of African savannas and woodlands, J. Geophys. Res.-Biogeo., 119, 1652-1669, 2014.

Hansen, J. and Lebedeff, S.: Global trends of measured surface air temperature, J. Geophys. Res., 92, 13345-13372, https://doi.org/10.1029/JD092iD11p13345, 1987.
Haran, T., Bohlander, J., Scambos, T., and Fahnestock, M.: MODIS mosaic of Antarctica (MOA) image map, National Snow and Ice Data Center, Digital media, Boulder, CO, USA, 2005.

Held, I. M. and Soden, B. J.: Water vapor feedback and global warming, Annu. Rev. Energ. Env., 25, 441-475, 2000.

Huntington, T. G.: Evidence for intensification of the global water cycle: review and synthesis, J. Hydrol., 319, 83-95, 2006.

Imaoka, K., Kachi, M., Kasahara, M., Ito, N., Nakagawa, K., and Oki, T.: Instrument performance and calibration of AMSR-E and AMSR2, International Archives of the Photogrammetry, Remote Sensing and Spatial Information Science, 38, 13-18, 2010.

Imaoka, K., Maeda, T., Kachi, M., Kasahara, M., Ito, N., and Nakagawa, K.: Status of AMSR2 instrument on GCOM-W1, Proc. SPIE, 852815, https://doi.org/10.1117/12.977774, 2012.

Jackson, T. J., Cosh, M. H., Bindlish, R., Starks, P. J., Bosch, D. D., Seyfried, M., Goodrich, D. C., Moran, M. S., and Du, J.: Validation of advanced microwave scanning radiometer soil moisture products, IEEE T. Geosci. Remote, 48, 4256-4272, 2010.

Jang, K., Kang, S., Kimball, J. S., and Hong, S. Y.: Retrievals of allweather daily air temperature using MODIS and AMSR-E data, Remote Sens., 6, 8387-8404, 2014.

Jones, L. A.: Synthesis of Satellite Microwave Observations for Monitoring Global Land-Atmosphere $\mathrm{CO}_{2}$ Exchange, Graduate Student Theses, Dissertations, Professional Papers, 10873, 2016.

Jones, L. A. and Kimball, J. S.: Daily Global Land Surface Parameters Derived from AMSR-E, Version 1, updated 2012, NASA National Snow and Ice Data Center Distributed Active Archive Center, Boulder, Colorado USA, https://doi.org/10.5067/JIKQZ6WO5C5M, last access: 1 October 2016, 2010.

Jones, L. A., Ferguson, C. R., Kimball, J. S., Zhang, K., Chan, S. T. K., McDonald, K. C., Njoku, E. G., and Wood, E. F.: Satellite microwave remote sensing of daily land surface air temperature minima and maxima from AMSR-E, IEEE J. Sel. Top. Appl., 3, 111-123, 2010.

Jones, M. O., Jones, L. A., Kimball, J. S., and McDonald, K. C.: Satellite passive microwave remote sensing for monitoring global land surface phenology, Remote Sens. Environ., 115, 1102-1114, 2011.

Jones, M. O., Jones, L. A., Kimball, J. S., and McDonald, K. C.: Satellite passive microwave detection of North America start of season, Remote Sens. Environ., 123, 324-333, 2012.

Jones, M. O., Kimball, J. S., and Jones, L. A.: Satellite microwave detection of boreal forest recovery from the extreme 2004 wildfires in Alaska and Canada, Glob. Change Biol., 19, 3111-3122, 2013.

Jones, M. O., Kimball, J. S., and Nemani, R. R.,: Asynchronous Amazon forest canopy phenology indicates adaptation to both water and light availability, Environ. Res. Lett., 9, 124021, https://doi.org/10.1088/1748-9326/9/12/124021, 2014.

Jones, P. D., New, M., Parker, D. E., Martin, S., and Rigor, I. G.: Surface air temperature and its changes over the past 150 years, Rev. Geophys., 37, 173-199, 1999.

Justice, C. O., Townshend, J. R. G., Vermote, E. F., Masuoka, E., Wolfe, R. E., Saleous, N., Roy, D. P., and Morisette, J. T.: An overview of MODIS land data processing and product status, Remote. Sens. Environ., 83, 3-15, 2002.

Kerr, Y. H., Waldteufel, P., Wigneron, J. P., Martinuzzi, J. A. M. J., Font, J., and Berger, M.: Soil moisture retrieval from space: 
The Soil Moisture and Ocean Salinity (SMOS) mission, IEEE T. Geosci. Remote, 39, 1729-1735, 2001.

Kim, Y., Kimball, J. S., Glassy, J., and Du, J.: An extended global Earth system data record on daily landscape freeze-thaw status determined from satellite passive microwave remote sensing, Earth Syst. Sci. Data, 9, 133-147, https://doi.org/10.5194/essd9-133-2017, 2017.

Koike, T., Nakamura, Y., Kaihotsu, I., Davva, G., Matsuura, N., Tamagawa, K. and Fujii, H.: Development of an Advanced Microwave Scanning Radiometer (AMSR-E) algorithm of soil moisture and vegetation water content, Proceedings of Hydraulic Engineering, 48, 217-222, 2004.

Liu, Y. Y., de Jeu, R. A., McCabe, M. F., Evans, J. P., and van Dijk, A. I.: Global long-term passive microwave satellite-based retrievals of vegetation optical depth, Geophys. Res. Lett., 38, L18402, https://doi.org/10.1029/2011GL048684, 2011.

Liu, Y. Y., Dijk, A. I., McCabe, M. F., Evans, J. P., and Jeu, R. A.: Global vegetation biomass change (1988-2008) and attribution to environmental and human drivers, Global Ecol. Biogeogr., 22, 692-705, 2013.

Lupascu, M., Welker, J. M., Seibt, U., Maseyk, K., Xu, X., and Czimczik, C. I.: High Arctic wetting reduces permafrost carbon feedbacks to climate warming, Nature Climate Change, 4, 51-55, 2014.

Maeda, E. E., Moura, Y. M., Wagner, F., Hilker, T., Lyapustin, A. I., Wang, Y., Chave, J., Mõttus, M., Aragão, L. E., and Shimabukuro, Y.: Consistency of vegetation index seasonality across the Amazon rainforest, Int. J. Appl. Earth Obs., 52, 4253, 2016.

Maeda, T., Taniguchi, Y., and Imaoka, K.: GCOM-W1 AMSR2 Level 1R Product: Dataset of Brightness Temperature Modified Using the Antenna Pattern Matching Technique, IEEE T. Geosci. Remote, 54, 770-782, 2016.

McVicar, T. R., Roderick, M. L., Donohue, R. J., Li, L. T., Van Niel, T. G., Thomas, A., Grieser, J., Jhajharia, D., Himri, Y., Mahowald, N. M., and Mescherskaya, A. V.: Global review and synthesis of trends in observed terrestrial near-surface wind speeds, Implications for evaporation, J. Hydrol., 416-417, 182205, 2012.

Meehl, G. A., Stocker, T. F., Collins, W. D., Friedlingstein, P., Gaye, A. T., Gregory, J. M., Kitoh, A., Knutti, R., Murphy, J. M., Noda, A., and Raper, S. C.: Global Climate Projections, in: Climate Change 2007: The Physical Science Basis. Contribution of Working Group I to the Fourth Assessment Report of the Intergovernmental Panel on Climate Change, edited by: Solomon, S., Qin, D., Manning, M., Chen, Z., Marquis, M., Averyt, K. B., Tignor, M., and Miller, H. L., Cambridge University Press, Cambridge, United Kingdom and New York, NY, USA, 3495, 747845, 2007.

Mladenova, I. E., Jackson, T. J., Njoku, E., Bindlish, R., Chan, S., Cosh, M. H., Holmes, T. R. H., De Jeu, R. A. M., Jones, L., Kimball, J., and Paloscia, S.: Remote monitoring of soil moisture using passive microwave-based techniques - Theoretical basis and overview of selected algorithms for AMSR-E, Remote Sens. Environ., 144, 197-213, 2014.

Mo, T., Choudhury, B. J., Schmugge, T. J., Wang, J. R., and Jackson, T. J.: A model for microwave emission from vegetation-covered fields, J. Geophys. Res., 87, 1229-1237, 1982.
Njoku, E. G., Jackson, T. J., Lakshmi, V., Chan, T. K., and Nghiem, S. V.: Soil moisture retrieval from AMSR-E, IEEE T. Geosci. Remote, 41, 215-229, 2003.

Panciera, R., Walker, J .P., Jackson, T. J., Gray, D. A., Tanase, M. A., Ryu, D., Monerris, A., Yardley, H., Rudiger, C., Wu, X., and Gao, Y.: The Soil Moisture Active Passive Experiments (SMAPEx): Toward soil moisture retrieval from the SMAP mission, IEEE T. Geosci. Remote, 52, 490-507, 2014.

Pinzon, J. E. and Tucker, C. J.: A non-stationary 1981-2012 AVHRR NDVI3g time series, Remote Sens., 6, 6929-6960, 2014.

Proud, S. R. and Rasmussen, L. V.: The influence of seasonal rainfall upon Sahel vegetation, Remote Sensing Letters, 2, 241-249, 2011.

Siebert, S., Döll, P., Hoogeveen, J., Faures, J.-M., Frenken, K., and Feick, S.: Development and validation of the global map of irrigation areas, Hydrol. Earth Syst. Sci., 9, 535-547, https://doi.org/10.5194/hess-9-535-2005, 2005.

Shi, J., Jackson, T., Tao, J., Du, J., Bindlish, R., Lu, L., and Chen, K. S.: Microwave vegetation indices for short vegetation covers from satellite passive microwave sensor AMSR-E, Remote Sens. Environ., 112, 4285-4300, 2008.

Smith, A. B., Walker, J. P., Western, A. W., Young, R. I., Ellett, K. M., Pipunic, R. C., Grayson, R. B., Siriwardena, L., Chiew, F. H. S., and Richter, H.: The Murrumbidgee soil moisture monitoring network data set, Water Resour. Res., 48, W07701, https://doi.org/10.1029/2012WR011976, 2012.

Smith, L. C., Sheng, Y., MacDonald, G. M., and Hinzman, L. D.: Disappearing arctic lakes, Science, 308, 1429-1429, 2005.

Tedesco, M. and Narvekar, P. S.: Assessment of the NASA AMSRE SWE product, IEEE J. Sel. Top. Appl., 3, 141-159, 2010.

Trenberth, K. E., Smith, L., Qian, T., Dai, A., and Fasullo, J.: Estimates of the global water budget and its annual cycle using observational and model data, J. Hydrometeorol., 8, 758-769, 2007.

Tucker, C. J., Pinzon, J. E., Brown, M. E., Slayback, D. A., Pak, E. W., Mahoney, R., Vermote, E. F., and El Saleous, N.: An extended AVHRR 8-km NDVI dataset compatible with MODIS and SPOT vegetation NDVI data, Int. J. Remote Sens., 26, 44854498, 2005.

Ulaby, F. T., Long, D. G., Blackwell, W. J., Elachi, C., Fung, A. K., Ruf, C., Sarabandi, K., Zebker, H. A., and Van Zyl, J.: Microwave Radar and Radiometric Remote Sensing, University of Michigan Press, Ann Arbor, Michigan, 2014.

Uma, K. N., Das, S. K., and Das, S. S.: A climatological perspective of water vapor at the UTLS region over different global monsoon regions: observations inferred from the Aura-MLS and reanalysis data, Clim. Dynam., 43, 407-420, 2014.

Van Huissteden, J., Berrittella, C., Parmentier, F. J. W., Mi, Y., Maximov, T. C., and Dolman, A. J.: Methane emission by permafrost thaw lakes limited by lake drainage, Nature Climate Change, 1, 119-123, 2011.

Walko, R. L., Band, L. E., Baron, J., Kittel, T. G., Lammers, R., Lee, T. J., Ojima, D., Pielke Sr., R. A., Taylor, C., Tague, C., and Tremback, C. J.: Coupled atmosphere-biophysics-hydrology models for environmental modelling, J. Appl. Meteorol. Clim., 39, 931-944, 2000.

Waltari, E., Schroeder, R., McDonald, K., Anderson, R. P., and Carnaval, A.: Bioclimatic variables derived from remote sensing: 
assessment and application for species distribution modelling, Methods in Ecology and Evolution, 5, 1033-1042, 2014.

Wang, J. R. and Manning, W.: Near concurrent MIR, SSM/T-2, and SSM/I observations over snow-covered surfaces, Remote Sens. Environ., 84, 457-470, 2003.

Watts, J. D., Kimball, J. S., Jones, L. A., Schroeder, R., and McDonald, K. C.: Satellite Microwave remote sensing of contrasting surface water inundation changes within the Arctic-Boreal Region, Remote Sens. Environ., 127, 223-236, 2012.

Watts, J. D., Kimball, J. S., Bartsch, A., and McDonald, K. C.: Surface water inundation in the boreal-Arctic: potential impacts on regional methane emissions, Environ. Res. Lett., 9, 075001, https://doi.org/10.1088/1748-9326/9/7/075001, 2014.

Wentz, F. J. and Meissner, T.: AMSR Ocean Algorithm, Algorithm Theoretical Basis Document, Remote Sensing Systems, 121599A-1, 59 pp., 2000.

Wentz, F. J., Ricciardulli, L., Hilburn, K., and Mears, C.: How much more rain will global warming bring?, Science, 317, 233-235, https://doi.org/10.1126/science.1140746, 2007.
Wild, M., Grieser, J., and Schär, C.: Combined surface solar brightening and increasing greenhouse effect support recent intensification of the global land-based hydrological cycle, Geophys. Res. Lett., 35, L17706, https://doi.org/10.1029/2008GL034842, 2008.

Yang, K., Qin, J., Zhao, L., Chen, Y., Tang, W., Han, M., Chen, Z., Lv, N., Ding, B., Wu, H., and Lin, C.: A MultiScale Soil Moisture and Freeze-Thaw Monitoring Network on the Third Pole, B. Am. Meteorol. Soc., 94, 1907-1916, https://doi.org/10.1175/BAMS-D-12-00203.1, 2013.

Zhu, Z., Piao, S., Myneni, R. B., Huang, M., Zeng, Z., Canadell, J. G., Ciais, P., Sitch, S., Friedlingstein, P., Arneth, A., and Cao, C. Greening of the Earth and its drivers, Nature Climate Change, 6, 791-795, https://doi.org/10.1038/nclimate3004, 2016. 